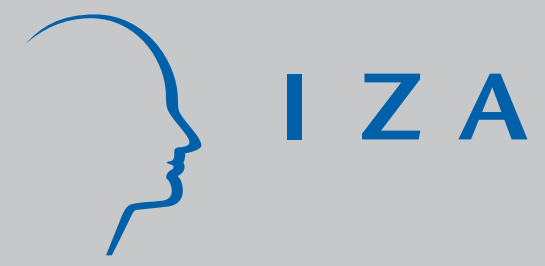

IZA DP No. 4683

International Specialization and the Return to Capital

Catia Batista

Jacques Potin

January 2010

Forschungsinstitut zur Zukunft der Arbeit Institute for the Study of Labor 


\title{
International Specialization and the Return to Capital
}

\author{
Catia Batista \\ Trinity College Dublin \\ and IZA \\ Jacques Potin \\ ESSEC Business School, Paris
}
Discussion Paper No. 4683
January 2010

\author{
IZA \\ P.O. Box 7240 \\ 53072 Bonn \\ Germany \\ Phone: +49-228-3894-0 \\ Fax: +49-228-3894-180 \\ E-mail: iza@iza.org
}

Any opinions expressed here are those of the author(s) and not those of IZA. Research published in this series may include views on policy, but the institute itself takes no institutional policy positions.

The Institute for the Study of Labor (IZA) in Bonn is a local and virtual international research center and a place of communication between science, politics and business. IZA is an independent nonprofit organization supported by Deutsche Post Foundation. The center is associated with the University of Bonn and offers a stimulating research environment through its international network, workshops and conferences, data service, project support, research visits and doctoral program. IZA engages in (i) original and internationally competitive research in all fields of labor economics, (ii) development of policy concepts, and (iii) dissemination of research results and concepts to the interested public.

IZA Discussion Papers often represent preliminary work and are circulated to encourage discussion. Citation of such a paper should account for its provisional character. A revised version may be available directly from the author. 


\section{ABSTRACT}

\section{International Specialization and the Return to Capital ${ }^{*}$}

How does factor accumulation affect the pattern of international specialization and returns to capital? We provide a new integrated treatment to this question using a panel of 44 developing and developed countries over the period 1976-2000. We confirm the HeckscherOhlin prediction that, with sufficient differences in country endowments, there is no factor price equalization and countries specialize in different subsets of goods. Innovatively, we obtain the returns to capital implied by this model: these are consistent with the Lucas paradox, which we explain after accounting for cross-country differences in the cost of capital goods. We also find that, along their development path, countries have often experienced structural change in the form of intra-industry specialization. Our findings are consistent with Ventura's hypothesis that growth can be promoted in this way through "beating the curse of diminishing returns" - indeed we find no decrease in the return to capital at any given capitallabor ratio despite capital accumulation by most countries within a cone of diversification.

JEL Classification: F11, F21, O40

Keywords: economic growth and international trade, Heckscher-Ohlin, multiple cones of diversification, marginal product of capital, return to capital, Lucas paradox, specialization

Corresponding author:

Catia Batista

Department of Economics

Trinity College Dublin

Dublin 2

Ireland

E-mail: catia.batista@tcd.ie

\footnotetext{
* We would like to thank Gino Cateau, Marcos Chamon, Nicolas Coeurdacier, Julian Di Giovanni, Sebnem Kalemli-Ozcan, Laurence Lescourret, Beata Javorcik, Patricia Langohr, Peter Neary, Radu Vranceanu, Adrian Wood and participants at a number of seminars and conferences for their comments on this and earlier versions. Excellent research assistance was provided by Christoph Lakner. Batista gratefully acknowledges financial support from the George Webb Medley Fund at the University of Oxford and from the Arts and Social Sciences Benefactions Fund at Trinity College Dublin.
} 


\section{Introduction}

The Heckscher-Ohlin (HO) model predicts that international specialization and trade are driven by differences in factor endowments. It is one of the most influential models in international economics because it has far-reaching implications for the level and distribution of income. For instance, the model predicts that, in rich countries, a growing trade with developing nations will increase the total income, along with a redistribution of income towards skilled workers and the owners of capital. In addition, as shown by Ventura (1997), trade facilitates growth in certain circumstances. Indeed, small countries that grow through capital accumulation should alter their specialization toward capital-intensive goods. This increases the demand for capital and thus sustains the return to capital and the incentives to accumulate even more capital. The combination of international trade and structural change can therefore bring about growth without decreasing returns. Another prediction of the HO model is that, if country endowments in effective factors are very different, there will be no factor price equalization (FPE), with a higher rental cost of capital in poor countries. This should lead to flows of capital to the less developed countries and to higher wages in these countries.

To study the essential mechanisms that involve international specialization, factor returns and capital accumulation, we proceed in two steps. We first show that the factor proportions model without FPE indeed provides a good description of what happened to 44 developing and developed countries over the period 1976-2000. Indeed, we find that the HO model actually explains specialization at an aggregate level in each cross section of countries, as well as changes in specialization that occur along the development path of each country.

In a second step, we study the implications of our model for factor returns and growth. In fact, while most previous works in the empirical literature on the HO model focus only on the relationship between factor endowments and specialization, our empirical approach generates direct estimates of workers' compensation and returns to capital (or the value of the marginal 
product of capital, MPK) in each country. ${ }^{1}$ With these estimates, we can check the internal consistency of our approach. We find that there is indeed no FPE, with higher implied wages in rich countries and higher implied returns to capital in the less developed countries. In addition, we provide an explanation of why, despite a higher return to capital in poor countries, capital does not flow systematically from rich to poor countries: the cost of capital adjusted for quality differences is much higher in these less developed countries. Finally, our results point to two factors that must have enhanced growth in most countries. Decomposing the changes over time in the countries' capital-labor ratios in within-industry changes and between-industry changes, we find that, for many countries, including the East Asian growth miracles, the structural transformation emphasized by Ventura (1997) mainly occurred within industries. This must have facilitated growth as it should be easier for firms to alter their industrial specialization from, say, rudimentary machinery to higher quality machinery (a change of specialization within an industry) than to switch from coarse textiles to high quality machinery (a change of specialization across industries). The second growth-enhancing factor is that, despite capital accumulation by most countries worldwide, the returns to capital have remained stable at fixed capital-labor ratios, thus sustaining the incentives to accumulate capital.

In this paper, the estimation of the HO model is based on the graphical approach by Deardorff $(1974) .^{2}$ This approach is particularly convenient for our purpose. First, it allows countries to specialize in a subset of goods. In the HO model, this is a necessary result when factor endowments are very different across countries: with highly heterogeneous endowments, there is no FPE and therefore countries must specialize in the subset of goods most suited to their endowments. While most previous studies in trade assumed that factor prices are equalized, more recent research provides evidence that there is no FPE and that OECD and poorer coun-

\footnotetext{
${ }^{1}$ In this paper, we use interchangeably "return to capital" and "value of the MPK".

${ }^{2}$ Kohli (1978) introduced an alternative methodology followed by Harrigan (1997) and Redding (2002). Given our focus on factor returns, the approach à la Deardorff (1974) seems more appropriate.
} 
tries belong to different cones of specialization (Debaere and Demiroglu, 2003; Schott, 2003). ${ }^{3}$ Accordingly, we choose cone frontiers so that OECD countries and most developing countries belong to different cones in 1990. Naturally, most countries move within their cone and some of them, like the East Asian "tigers", join the capital-rich cone at some point in the period 19762000. The second convenient property of Deardorff's (1974) approach is that, as we shall show, it can be readily augmented with (Hicks-neutral) total factor productivity (TFP) differences à la Trefler (1995). Accounting for these TFP differences is important: TFP differences do exist and, as found by Fitzgerald and Hallak (2004), their omission could introduce important biases in the empirical estimation of the HO model. For example, consider the realistic case in which there is a positive correlation between a country's TFP and its capital-labor ratio. In such a case, if TFP differences are not properly accounted for, the return to capital in poor countries is overestimated. As our work focuses precisely on factor returns, it is all the more crucial to estimate and correct for the TFP differences.

Because the theoretical model defines goods or industries based on capital intensity in production, whereas the usual ISIC classification defines industries according to their end-use, we recast industry data in two more theoretically-appropriate "Heckscher-Ohlin aggregates", i.e. sets of goods with similar factor intensities for each country-period, following Schott (2003). To understand the adequacy of this adjustment consider, for instance, the various national transport industries in 1990. Germany specializes in luxury cars and aircraft produced with capital-intensive techniques. Hence, the German transport industry in 1990 belongs to the capital-intensive HO aggregate. On the contrary, Malaysia is rather specialized in the production of bicycles produced with more labor-intensive techniques, and the Malaysian transport industry is classified in the labor-intensive $\mathrm{HO}$ aggregate. We thus explicitly recognize the

\footnotetext{
${ }^{3}$ The well-known work by Trefler (1993) is original in that it specifically confronts the fact that factor prices are clearly not equalized and, as the present work, it provides estimates of factor returns. But Trefler (1993) still assumes that countries belong to the same cone: in his article, differences are not driven by factor proportions, but only by productivity differences. For instance, the cost of an "effective" unit of labor is assumed to be the same in the US and in Bangladesh.
} 
important within-industry heterogeneity in terms of factor intensities. ${ }^{4}$

Moreover, we correct for factor quality in a simple way. To account for differences in the stock of human capital across countries and over time, we employ the Barro and Lee (2001) data on educational attainment, à la Trefler (1993). To get comparable quantities of capital across countries, we estimate quality-equivalent stocks of capital using the results of Eaton and Kortum (2001), who use data on the international trade of equipment goods to infer the price of quality-equivalent capital in the various countries.

As stated earlier, we find that, despite capital accumulation by most countries, the returns to capital at fixed effective capital-labor ratios have remained stable over time. We come to this result as follows. As will be clear later, the estimation of the HO model following Deardorff (1974) is greatly facilitated when the frontiers between the cones are fixed over time. We here make the null hypothesis that the cone cutoffs are constant over time and check that the conditions for this stability are satisfied. These frontiers should remain fixed whenever the relative "profitability" of the two $\mathrm{HO}$ aggregates is constant over time. For that, it must be that the joint impact of price changes and technology changes is the same for both aggregates. ${ }^{5}$ Testing for this hypothesis, we find that, for both aggregates, this joint impact of price and technology changes is not economically or statistically significant over the period 1976-2000. For the capital-intensive goods for instance, even though the growth of most countries (including the East Asian countries) has drastically increased the world supply of these goods, it has not become less profitable to produce these goods. Our results imply the claimed result that factor returns for a given capital-labor ratio have remained fixed over time. Combining this result with the one of a constant MPK in the diversification cone (proven theoretically by Ventura (1997) for the case with two goods), we obtain that the value of the MPK, or the return to capital,

\footnotetext{
${ }^{4}$ With product-level U.S. import data, Schott (2004) finds that factor heterogeneity also exists at the product level, with capital and skill abundant countries specializing in high value products.

${ }^{5}$ For instance, in the celebrated Lerner (1952) diagram, specialization and the frontiers of the cone of diversification are determined by the location of the two unit-value isoquants with equations $f_{a}(L, K)=1 / p_{a}$, with $a=l$ for the labor-intensive good and $a=k$ for the capital-intensive good.
} 
has not decreased over time for the countries in this cone. ${ }^{6}$ This means that the "miracle" economies in East Asia could enjoy economic growth without decreasing returns while moving within the cone of diversification.

As in the standard HO model with multiple cones, and despite TFP differences across countries, we find that the returns to capital tend to be higher in poor countries. So how can we explain the Lucas paradox? In other words, why is it the case that we observe no systematic flow of capital from rich to poor countries? Our explanation is the following: once we take into account the fact that the cost of capital adjusted for quality differences is much higher in these countries as found by Eaton and Kortum (2001), the advantage due to the rate-of-return differential vanishes. Indeed, the financial rate of return to capital investment is not higher in poor countries. For an investor, not much is to be gained from a systematic reallocation of capital from rich to poor countries. We therefore confirm the empirical finding of Caselli and Feyrer (2007) although we follow a totally different approach: the value of the MPK is higher in poor countries; the financial rates of return of investing in manufacturing are much more similar across countries; and the reason for this is the higher relative price of capital goods in poor countries.

Related papers in the literature are Davis and Weinstein (2001) and Debaere and Demiroglu (2003): we adopt the common approach towards modifying the original HO model, but we use the time dimension in our panel and focus in exploring the model's implications for factor returns and specialization patterns over timeand we also study both developed and developing countries (and not only OECD countries). Relative to Schott (2003), we follow his approach to tackle intra-industry heterogeneity and estimate multiple cones; but we consider the role of differences in technology and factor quality, plus we use panel data which enables us to use the time dimension to explore the model's implications for factor returns and specialization patterns

\footnotetext{
${ }^{6}$ Debaere and Demiroglu (2006) also conduct an empirical work on the same topic, but they do not verify one of the elements at the heart of the mechanism, namely the stability over time of the value of the MPK for the "miracle" economies.
} 
over time. Finally, we share a common focus on FPE (or its breakdown) and specialization in production with Hanson and Slaughter (2002), Bernard et al. (2005, 2009) and Chiquiar (2008), but those papers focus on a single country (Mexico, US and UK).

The remainder of the paper is organized as follows. Section 2 estimates the production side of the traditional Heckscher-Ohlin model. Section 3 focuses on the returns to capital implied by our model and exposes the implications of our results in terms of growth. The last section concludes.

\section{The production side of the Heckscher-Ohlin model}

Our theoretical framework is the traditional $2 \times 2$ Heckscher-Ohlin model. We shall explain in this section how we make it empirically operational. We will also give arguments for selecting this particular model.

\subsection{Deardorff's (1974) graphical approach to specialization}

Consider $N$ countries, $n=1, \ldots, N$. At date $t$, country $n$ is endowed with a quantity $K_{n}^{t}$ of capital and a quantity $L_{n}^{t}$ of labor. There are two goods that can be produced in each country: good $l$ is labor-intensive, and good $k$ is capital-intensive. There is no factor intensity reversal. Factors are mobile between sectors, but immobile internationally. Both goods are produced with constant returns to scale (CRS) by competitive firms, and the marginal product of each factor is positive and decreasing at the firm (and industry) level. For the moment, we assume that all countries have access to the same technology. Each country is small and can freely trade goods on the world market at date- $t$ prices.

In a competitive equilibrium, when factor endowments are sufficiently different, countries cannot lie in the FPE set. As factor prices are not equalized, countries have to specialize 
according to their endowments: they are located in different cones of specialization. The countries with a low capital-labor ratio $\left(K_{n}^{t} / L_{n}^{t} \in\left[\tau_{0}=0 ; \tau_{1}^{t}\right]\right)$ specialize in the production of the labor-intensive good. The countries with an intermediate capital-labor ratio $\left.\left.\left(K_{n}^{t} / L_{n}^{t} \in\right] \tau_{1}^{t} ; \tau_{2}^{t}\right]\right)$ produce the two goods. The countries with a high capital-labor ratio $\left.\left.\left(K_{n}^{t} / L_{n}^{t} \in\right] \tau_{2}^{t} ; \tau_{3}=+\infty\right)\right)$ specialize in the production of the capital-intensive good. In this setting, $\tau_{1}^{t}$ and $\tau_{2}^{t}$ are the two possibly time-varying boundaries of the cone of diversification.

More precisely, the countries with a low capital endowment produce only the labor-intensive good with an output per worker given by:

$$
\frac{Q_{l n}^{t}}{L_{n}^{t}}=F_{l}\left(K_{n}^{t}, L_{n}^{t}\right) / L_{n}^{t}=f_{l}\left(\frac{K_{n}^{t}}{L_{n}^{t}}\right)
$$

where $n$ denotes a country (or "nation"), and $t$ a date. $F_{l}($.$) denotes the production function$ for the labor-intensive good, and $f_{l}(k) \equiv F_{l}(k, 1)$ is the production function in intensive form and is concave. Note that in the previous equation but also in the following ones, $L_{n}^{t}$ denotes the total quantity of labor employed in the manufacturing sector of country $n$ at date $t$.

For the countries in the cone of diversification, the output per worker for good $a$ is given by:

$$
\frac{Q_{a n}^{t}}{L_{n}^{t}}=\alpha_{a}^{t}+\beta_{a}^{t} \frac{K_{n}^{t}}{L_{n}^{t}}
$$

with $\alpha_{l}^{t}>0, \beta_{l}^{t}<0, \alpha_{k}^{t}=0, \beta_{k}^{t}>0$, and $a=k, l$. The countries with a high capital endowment specialize in the production of the capital-intensive good:

$$
\frac{Q_{k n}^{t}}{L_{n}^{t}}=F_{k}\left(K_{n}^{t}, L_{n}^{t}\right) / L_{n}^{t}=f_{k}\left(\frac{K_{n}^{t}}{L_{n}^{t}}\right)
$$

where $F_{k}($.$) denotes the production function for the capital-intensive good, and f_{k}($.$) is concave.$

Following Deardorff $(1974,2000)$, Figure 1 represents the theoretically implied patterns of specialization. The dashed line represents the value added of the labor-intensive good divided by the total number of workers in manufacturing over a country's "development path". Similarly, the solid line represents value added per worker for the capital-intensive good. The 
Rybczynski effect says that, with fixed prices and technologies, capital accumulation in the cone of diversification leads to a reduced production of the labor-intensive good and to an increased production of the capital-intensive good. The thin straight line that is tangent to the two curves determines the capital-labor ratios in the two industries (equal to $\tau_{1}^{t}$ and $\tau_{2}^{t}$ ). Figure 2 shows total value added per worker for the various levels of capital per worker. One can also prove that the slope of the value added per capita curve (in Figure 2) is equal to the rental cost of capital, and that the intercept of the tangent to this curve with the vertical axis is the compensation per worker.

$<$ Figure 1 here. $>$

$<$ Figure 2 here. $>$

It is also well-known that a change in the relative price of the two goods or biased technological progress should modify the structure of industrial production. For instance, if the relative price of the capital-intensive good goes up or if technological progress is biased in its direction, then the two cone cutoffs should move to the left, with more countries producing the capital-intensive goods and each country in the cone of diversification producing relatively more of the capital-intensive goods.

A useful property of the model is that we can estimate it with no particular assumption about demand. For instance, we do not have to make the "consumption similarity" assumption that is used more or less explicitly in the works on the factor content of trade. ${ }^{7}$ Demand factors are still important, but only through their effects on prices.

\subsection{Empirical approach}

We focus on the manufacturing sector as it should contain fewer non-tradables than other sectors of the economy, such as the agricultural or the service sectors. This choice makes it more

\footnotetext{
${ }^{7}$ See Trefler and Zhu (2005) for a discussion of the "consumption similarity" condition.
} 
reasonable the assumption that, whatever their location, all firms producing similar goods can sell these goods at the same price. Of course, including the agricultural and service sectors could provide a stricter test of the model at stake.

A continuum of goods We now give some empirical content to the textbook model with two goods. In reality, much more than two goods are produced. Suppose that there are actually three cones (one of diversification, two of specialization), with rental costs of capital varying across cones but constant within a single cone. ${ }^{8}$ Theory implies that a country in a given cone should produce goods such that the unit-value isoquant is tangent to the cone's isocost line. Figure 3 shows this with a diagram similar to the one in Lerner (1952).

\section{$<$ Figure 3 here. $>$}

This situation provides strong predictions that are contradicted by the data. For instance, they imply that a country with a capital-labor ratio $K_{n} / L_{n}$ just above $\tau_{i}$ will only produce goods with a capital-labor ratio at $K / L=\tau_{i}$ or just above.

We rather rely on a specification that yields desirable theoretical properties and seems empirically appropriate, as shown later. In the spirit of Dornbusch et al. (1980), we assume that each country produces a continuum of goods with various capital-labor intensities. Country $n$ is populated by a continuum of workers with a total mass $L_{n}$. This country is also endowed with $K_{n}$ units of capital. Omitting the time superscript, let $\tau_{1}$ and $\tau_{2}$ be the two cone cutoffs. Each worker is indexed by $i$, with $i$ uniformly distributed on the interval [0;1]. We suppose that worker $i$ works in a production facility with a capital-labor ratio $\frac{K}{L}(i)=\frac{K_{n}}{L_{n}} \frac{2\left(\tau_{1}+i\left(\tau_{2}-\tau_{1}\right)\right)}{\tau_{1}+\tau_{2}}$. This implies that country $n$ produces goods with $\frac{K}{L}(i) \in\left[\frac{K_{n}}{L_{n}} \frac{2 \tau_{1}}{\tau_{1}+\tau_{2}} ; \frac{K_{n}}{L_{n}} \frac{2 \tau_{2}}{\tau_{1}+\tau_{2}}\right]$. This also implies that country $n$ 's capital-labor ratio is $K_{n} / L_{n}$ as required. With this modelling strategy, a

\footnotetext{
${ }^{8}$ In this section, to make the exposition simpler, we make the assumption that the return to capital is constant within each cone. Later in the paper, we shall assume that the return to capital is decreasing within the capital-rich cone, just as in the standard $2 \times 2$ model.
} 
country produces goods that it should not produce in the "pure" model with free trade (like in Dornbusch et al., 1980).

With these assumptions a country with a capital-labor ratio equal to $\tau_{1}$ produces goods such that $\frac{K}{L}(i) \in\left[\frac{2 \tau_{1}^{2}}{\tau_{1}+\tau_{2}} ; \frac{2 \tau_{1} \tau_{2}}{\tau_{1}+\tau_{2}}\right]$, while a country with a capital-labor ratio equal to $\tau_{2}$ produces

goods such that $\frac{K}{L}(i) \in\left[\frac{2 \tau_{1} \tau_{2}}{\tau_{1}+\tau_{2}} ; \frac{2 \tau_{2}^{2}}{\tau_{1}+\tau_{2}}\right]$. There is therefore a cutoff $q\left(\tau_{1}, \tau_{2}\right)=\frac{2 \tau_{1} \tau_{2}}{\tau_{1}+\tau_{2}}$ such that countries in the labor-rich cone produce only goods with a capital-labor ratio below $q$, and countries in the capital-rich cone produce only goods with a capital-labor ratio above $q$. This cutoff $q$ is shown in Figure 4.

\section{$<$ Figure 4 here. $>$}

The Heckscher-Ohlin aggregates Given the above specification and the good cutoff, we can follow Schott (2003) and define "Heckscher-Ohlin aggregates". The labor-intensive HO aggregate is the set of goods such that $\frac{K}{L}(i) \leq q$, while the capital-intensive aggregate is the set of goods such that $\frac{K}{L}(i)>q$. As we do not have data on specific goods but only on International Standard Industrial Classification (ISIC) industries, we shall measure the total value-added of the labor-intensive aggregate produced by country $n$ as:

$$
V A_{l n}^{t}\left(\tau_{1}, \tau_{2}\right)=\sum_{\substack{K_{i n}^{t} \\ L_{i n}^{t}} q\left(\tau_{1}, \tau_{2}\right)} V A_{i n}^{t}
$$

while the production of the capital-intensive aggregate is equal to:

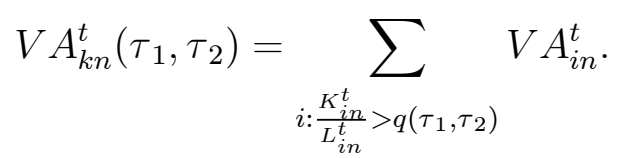

We thus aggregate industries according to their capital-intensity rather than according to their end use (as most classifications such as the ISIC do), as in the HO model. A number of examples may illustrate the importance of this method: for instance, in Schott's (2003) preferred model, 
the footwear industry in Panama is classified as belonging to a labor-intensive aggregate, while the Italian footwear industry belongs to an aggregate with a higher capital intensity. For any ISIC industry, cross-country differences in factor intensity might reflect, beyond factor substitution, the fact that countries specialize in goods that differ in quality. It might also be the result of an international fragmentation of the production process, with the labor-rich countries specializing in the production stages that are labor-demanding. The aggregation has important consequences. Most importantly, goods are defined according to their capital intensity as in the production side of the HO model. In addition, this strategy allows us to reduce the number of "goods".

We take the results by Debaere and Demiroglu (2003) and Schott (2003) as evidence that countries lie in different cones. Specifically, we assume that countries belong to one of three cones. Also by assumption, the marginal product of capital is constant within each of the first two cones, but decreasing in the third one. We denote by $w_{c}$ and $r_{c}$ the wage and the rental cost of capital in cone $c=1,2$. In the third cone, both the wage and the rental cost of capital depend on $K_{n} / L_{n}$. They are denoted $w_{3}\left(K_{n} / L_{n}\right)$ and $r_{3}\left(K_{n} / L_{n}\right)$. The marginal product of capital (MPK) in the third cone is decreasing, just as in the textbook $2 \times 2$ model. ${ }^{9}$ Our specification also implies the sensible result that, when moving from the second cone to the third one, there is no jump in the MPK.

In country $n$ with a capital-labor ratio $K_{n} / L_{n}$, the value added for the labor-intensive aggregate is, once divided by the total number of workers in manufacturing, given by:

$$
\begin{aligned}
\frac{V A_{l n}\left(\tau_{1}, \tau_{2}\right)}{L_{n}} & =w_{1}+r_{1} \frac{K_{n}}{L_{n}} \text { if } \frac{K_{n}}{L_{n}} \leq \tau_{1} \\
& \left.\left.=w_{2} \frac{\frac{\tau_{1} \tau_{2}}{K_{n} / L_{n}}-\tau_{1}}{\tau_{2}-\tau_{1}}+r_{2} \frac{\frac{\tau_{1}^{2} \tau_{2}^{2}}{K_{n} / L_{n}}-\tau_{1}^{2} K_{n} / L_{n}}{\tau_{2}^{2}-\tau_{1}^{2}} \text { if } \frac{K_{n}}{L_{n}} \in\right] \tau_{1} ; \tau_{2}\right] ; \\
& =0 \text { if } \frac{K_{n}}{L_{n}}>\tau_{2},
\end{aligned}
$$

\footnotetext{
${ }^{9}$ This is consistent with Davis and Weinstein (2001) who find systematic differences across OECD countries in industry factor usage in nontraded sectors.
} 
and, for the capital-intensive aggregate, it is:

$$
\begin{aligned}
\frac{V A_{k n}\left(\tau_{1}, \tau_{2}\right)}{L_{n}} & =0 \text { if } \frac{K_{n}}{L_{n}} \leq \tau_{1} \\
& \left.\left.=w_{2} \frac{\tau_{2}-\frac{\tau_{1} \tau_{2}}{K_{n} / L_{n}}}{\tau_{2}-\tau_{1}}+r_{2} \frac{\tau_{2}^{2} K_{n} / L_{n}-\frac{\tau_{1}^{2} \tau_{2}^{2}}{K_{n} / L_{n}}}{\tau_{2}^{2}-\tau_{1}^{2}} \text { if } \frac{K_{n}}{L_{n}} \in\right] \tau_{1} ; \tau_{2}\right] ; \\
& =w_{3}\left(K_{n} / L_{n}\right)+r_{3}\left(K_{n} / L_{n}\right) \frac{K_{n}}{L_{n}} \text { if } \frac{K_{n}}{L_{n}}>\tau_{2} .
\end{aligned}
$$

To ensure the continuity of the value-added functions at $\tau_{1}$, we impose $w_{1}+r_{1} \tau_{1}=w_{2}+r_{2} \tau_{1}$. For simplicity, we assume $w_{1}=0$. If production in the third cone production is given by $F_{n}\left(K_{n}, L_{n}\right)=A K_{n}^{1-\beta} L_{n}^{\beta}$, i.e. a simple Cobb-Douglas production function augmented by a TFP factor, $A$, the marginal product of labor in country $n$ is $\beta A\left(K_{n} / L_{n}\right)^{1-\beta}$ and the marginal product of capital is $(1-\beta) A\left(K_{n} / L_{n}\right)^{-\beta}$. Using the fact that a country with $K_{n} / L_{n}=\tau_{2}$ is both in the second cone and in the third cone, we can rewrite the marginal product of labor for a country with $K_{n} / L_{n}>\tau_{2}$ as $w_{3}\left(K_{n} / L_{n}\right)=w_{2}\left(\frac{K_{n} / L_{n}}{\tau_{2}}\right)^{(1-\beta)}$ and the marginal product of capital in the same country as $r_{3}\left(K_{n} / L_{n}\right)=r_{2}\left(\frac{K_{n} / L_{n}}{\tau_{2}}\right)^{-\beta}$. Figure 5 shows the specialization patterns implied by our assumptions.

$<$ Figure 5 here. $>$

By considering the possibility that countries lie in different cones, Schott (2003) introduced non-linearities in the value added per worker, with the non-linearities occuring at the cone frontiers. Here we even have non-linearities within each cone. This does not contradict theory. While simpler, the linear form might be considered, as Fitzgerald and Hallak (2004) put it, a "knife-edge" result derived under very strong assumptions. But once we depart from the textbook case with a number of produced goods equal to the number of factors, there is no reason for linearity to hold at the good or HO-aggregate level.

Notice that this specification introduces restrictions across $\mathrm{HO}$ aggregates. Thus, on the one hand, our specification is less restrictive than Schott's (2003) as we allow for TFP differences 
across countries, but, on the other hand, we impose restrictions across aggregates that do not appear in his paper. ${ }^{10}$

International differences in total factor productivity With Hicks-neutral total factor productivity differences across countries, wages and rental rates of capital differ across countries. Figure 6 shows the effect of such productivity differences: for a relatively productive country $n$, the production levels of the two aggregates are multiplied by the same factor. This is a pure scale effect.

\section{$<$ Figure 6 here. $>$}

We denote $w_{c n}$ and $r_{c n}$ the wage and rental cost of capital in country $n$ when it is located in cone $c=1,2$. We make the assumption that we also have $r_{2 n}=\alpha r_{1 n}$, with $\alpha<1$, for all $n$ : moving from the first cone to the second one leads to the same (proportional) reduction in the marginal product of capital for all countries. Using the above continuity constraints, we get $w_{2 n}=(1-\alpha) \tau_{1} r_{1 n}$

We obtain the following system of equations:

$$
\begin{gathered}
\frac{V A_{l n}\left(\tau_{1}, \tau_{2}\right)}{L_{n}}=r_{1 n} f_{l}\left(K_{n} / L_{n}, \alpha, \tau_{1}, \tau_{2}\right), \\
\frac{V A_{k n}\left(\tau_{1}, \tau_{2}\right)}{L_{n}}=r_{1 n} f_{k}\left(K_{n} / L_{n}, \tau_{1}, \tau_{2}, \alpha, \beta\right),
\end{gathered}
$$

with

$$
\begin{aligned}
f_{l}\left(K_{n} / L_{n}, \tau_{1}, \tau_{2}, \alpha\right) & =\frac{K_{n}}{L_{n}} \text { if } \frac{K_{n}}{L_{n}} \leq \tau_{1} ; \\
& \left.\left.=\tau_{1}(1-\alpha) \frac{\frac{\tau_{1} \tau_{2}}{K_{n} / L_{n}}-\tau_{1}}{\tau_{2}-\tau_{1}}+\alpha \frac{\frac{\tau_{1}^{2} \tau_{2}^{2}}{K_{n} / L_{n}}-\tau_{1}^{2} K_{n} / L_{n}}{\tau_{2}^{2}-\tau_{1}^{2}} \text { if } \frac{K_{n}}{L_{n}} \in\right] \tau_{1} ; \tau_{2}\right] \\
& =0 \text { if } \frac{K_{n}}{L_{n}}>\tau_{2},
\end{aligned}
$$

\footnotetext{
${ }^{10}$ Such restrictions do exist in the model with two factors of production, but they are not necessarily valid in more general models. For instance, this will be the case if endowments in natural resources and land favor specialization in one of the HO aggregates. See Leamer (1987) and Schott (2003). For simplicity, we abstract from these effects.
} 
and

$$
\begin{aligned}
f_{k}\left(K_{n} / L_{n}, \tau_{1}, \tau_{2}, \alpha, \beta\right) & =0 \text { if } \frac{K_{n}}{L_{n}} \leq \tau_{1} \\
& \left.\left.=\tau_{1}(1-\alpha) \frac{\tau_{2}-\frac{\tau_{1} \tau_{2}}{K_{n} / L_{n}}}{\tau_{2}-\tau_{1}}+\alpha \frac{\tau_{2}^{2} K_{n} / L_{n}-\frac{\tau_{1}^{2} \tau_{2}^{2}}{K_{n} / L_{n}}}{\tau_{2}^{2}-\tau_{1}^{2}} \text { if } \frac{K_{n}}{L_{n}} \in\right] \tau_{1} ; \tau_{2}\right] \\
& =\left[(1-\alpha) \tau_{1} \tau_{2}^{(\beta-1)}+\alpha \tau_{2}^{\beta}\right]\left(K_{n} / L_{n}\right)^{(1-\beta)} \text { if } \frac{K_{n}}{L_{n}}>\tau_{2}
\end{aligned}
$$

which must hold for each $n$.

International differences in factor quality We take into account factor quality differences across countries. Let $z_{f n}^{t}$ be the quality of factor $f=K, L$, in country $n$ at date $t$. If $K_{n}^{t}$ is the measured quantity of capital and $L_{n}^{t}$ is the measured quantity of labor, then the quantities of capital and labor adjusted for quality are $K_{n}^{* t}=z_{k n}^{t} K_{n}^{t}$, and $L_{n}^{* t}=z_{l n}^{t} L_{n}^{t}$. The way we obtain estimates of these quality factors is detailed in the data section that follows. As we try to be as close as possible to the traditional $2 \times 2$ model, the relevant quantities of labor and capital are the ones used in the manufacturing sector: in the cone of diversification, the production of each aggregate is dictated by the factor proportion in each sector and the quantity of factors employed in manufacturing. ${ }^{11}$

Changes in technologies or relative prices As we do not focus on a cross section but instead consider panel data, we must consider the impact of technological progress and of price changes over time. In order to measure these changes, we introduce multiplicative time dummies, denoted $\delta_{k}^{t}$ and $\delta_{l}^{t}$, specific to each aggregate but common to all countries. This modelling assumption is simple and in the spirit of the HO model. It is correct if the law of one price holds at the producer level for manufacturing goods produced with similar factor intensities, and if, for each $\mathrm{HO}$ aggregate, all countries face the same rate of technological progress. Changes over time of $\delta_{a}^{t}$ lead to a scale effect that shifts in the same proportion all

\footnotetext{
${ }^{11}$ This is also the approach followed by Schott (2001).
} 
the production levels of the $a$ aggregate in any cross section of countries. ${ }^{12}$ The other scale effect is due to the TFP differences (that appear here through the $r_{1 n}$ 's): it is country-specific and shifts all production levels in the country time series. We finally obtain the empirical model we estimate:

$$
\begin{gathered}
\frac{V A_{l n}^{t}\left(\tau_{1}, \tau_{2}\right)}{L_{n}^{* t}}=\left(1+\delta_{l}^{t}\right) r_{1 n} f_{l}\left(K_{n}^{* t} / L_{n}^{* t}, \tau_{1}, \tau_{2}, \alpha\right)+\epsilon_{l n}^{t}, \\
\frac{V A_{k n}^{t}\left(\tau_{1}, \tau_{2}\right)}{L_{n}^{* t}}=\left(1+\delta_{k}^{t}\right) r_{1 n} f_{k}\left(K_{n}^{* t} / L_{n}^{* t}, \tau_{1}, \tau_{2}, \alpha, \beta\right)+\epsilon_{k n}^{t},
\end{gathered}
$$

with $\delta_{k}^{t}=0$ for the first period in the panel and the $f_{a}($.$) functions given in Equations 4-9.13$ Here, $r_{1 n}$ is the rental cost of capital of country $n$ in the first, labor-rich cone during the first period. But, if country $n$ is in fact in the cone of diversification during the first period, $r_{1 n}$ is the hypothetical rental cost of capital country $n$ would have in the first cone, and $r_{2 n}=\alpha r_{1 n}$ is its actual rental rate.

If our restrictions across aggregates are correct and if technological progress and value changes are the same for the two aggregates, we have:

$$
\delta_{l}^{t}=\delta_{k}^{t}, \forall t
$$

If we can confirm this result empirically, it would validate our null hypothesis that the cone cutoffs have been stable over time. Without technological progress or value changes for the two

\footnotetext{
${ }^{12}$ This means that all countries specialized in the production of a given aggregate should face similar rates of technological progress. On the other hand, countries with different specializations might have measured TFP growth rates that differ.

${ }^{13}$ The dummies $\delta_{l}^{t}$ and $\delta_{k}^{t}$ indeed measure both technological changes and relative price changes. As explained in section 2.3 , we employ data on value added in current national currency. Denoting $F_{a n}(\cdot)$ the production function for aggregate $a$ in country $n$ in 1996, $\gamma_{a}^{t}$ the rate of Hicks-neutral technological progress for aggregate $a$ between 1996 and date $t$ (assumed to be the same for all countries), $D_{a n}^{1996, t}$ the price deflator for aggregate $a$ in country $n$, and $e_{n, \$}^{1996}$ the 1996 exchange rate, the observed value added in current national currency is $D_{a n}^{1996, t}\left(1+\gamma_{a}^{t}\right) F_{a n}(\cdot) e_{n}^{1996}$. We deflate value added data by the national consumption deflator $D_{n c}^{1996, t}$ and convert it into 1996 U.S. dollars using the 1996 exchange rate. We thus obtain for aggregate $a$ in country $n$ at date $t$ a value added given by $\frac{D_{a n}^{1996, t}\left(1+\gamma_{a}^{t}\right)}{D_{c n}^{11996, t}} F_{a n}(\cdot)$. Here we denote $r_{1 n} f_{a}(\cdot)$ the 1996 production function in intensive form for country $n$. In Equations $10-11,\left(1+\delta_{a}^{t}\right)$ is thus a weighted average of the various $\frac{D_{a n}^{1996, t}\left(1+\gamma_{a}^{t}\right)}{D_{c n}^{1996, t}}$ : it measures 1) the technological change for the HO aggregate $a$ and 2) the change in the relative price of the goods in the $a$ aggregate (relatively to the consumption goods).
} 
aggregates, we have:

$$
\delta_{a}^{t}=\delta_{a}^{t^{\prime}}=0, \forall t \neq t^{\prime}, a=k, l
$$

This other result would indicate that the combined effect of price and technology changes have been negligible. Denoting by $\mathbf{X}$ the matrix of explanatory variables, we assume $E\left[\epsilon_{n a}^{t} \mid \mathbf{X}\right]=0$, $E\left[\epsilon_{n a}^{t} \epsilon_{n a}^{t} \mid \mathbf{X}\right]=\sigma_{a}^{2}$, as well as $E\left[\epsilon_{n a}^{t} \epsilon_{n^{\prime} a^{\prime}}^{t^{\prime}} \mid \mathbf{X}\right]=0$, if $n \neq n^{\prime}$ and/or $t \neq t^{\prime}$ and/or $a \neq a^{\prime}$. The coefficients $\delta_{k}^{t}, \delta_{l}^{t}, \alpha, \beta$, and $r_{1 n}$ are estimated with Non Linear Least Squares. Note that we do not assume that the error term is multiplicative and that we do not take logs in Equations $10-11$.

We rely on previous works to choose the cone cutoffs $\tau_{1}$ and $\tau_{2}$, as well as the implied cone cutoff, $q\left(\tau_{1}, \tau_{2}\right)$. With a methodology that we build on, Schott (2003) presents evidence that countries in 1990 were lying in two cones of diversification, i.e. two cones without diminishing returns within each cone. He chooses a cone cutoff such that the OECD countries lie in the capital-rich cone and most of the less developed countries lie in a labor-rich cone. Debaere and Demiroglu (2003) use the "lens condition" of Deardorff (1994) to show that, also in 1990, the OECD countries with endowments sufficiently similar lied in the same cone, but the poorer countries were too rich in labor to be in this cone. Building on these works, we choose two cutoffs $\left(\tau_{1}=1,500\right.$ and $\left.\tau_{2}=15,000\right)$ such that the OECD countries were all located in the same cone around $1990\left(K_{n}^{*} / L_{n}^{*} \in\right] \tau_{2},+\infty[)$, and most developing countries lie in another cone (with $\left.\left.K_{n}^{*} / L_{n}^{*} \in\right] \tau_{1}, \tau_{2}\right]$ ). Consistent with Xu (2003), the poorest countries (Bangladesh and Sri Lanka in this paper) are located in a third cone (with $\left.K_{n}^{*} / L_{n}^{*} \in\left[0, \tau_{1}\right]\right){ }^{14}$

\footnotetext{
${ }^{14}$ Our model is close to the one selected by Schott (2003) for the cross section he studies (year 1990). He ignores the first cone, the one specialized in the labor-intensive aggregate, but we assume that there are only two countries in that cone anyway. He assumes that the OECD cone is a cone of diversification, the countries producing both capital-intensive goods and goods with an average capital intensity. We instead group all these goods in a single aggregate.
} 


\subsection{Data and construction of the main variables}

We use data from the United Nations Industrial Development Organization (UNIDO, 2005a,b) and the Penn World Table version 6.1 (PWT) (Heston et al., 2002). The UNIDO data set at the 3-digit level presents data for 28 sectors, but several countries aggregate data for two or more sectors (like "food products" and "beverages") into a larger one. To appropriately recognize missing data, we follow Koren and Tenreyro (2007) and aggregate sectors so as to obtain a consistent classification across countries. This leaves us with the 19 sectors or industries listed in Table 1.

$<$ Table 1 here.>

To estimate the model, we use 5-year averages for the periods 1976-1980, 1981-1985, 19861990, 1991-1995, and 1996-2000. We use the data for a country in a given period when they are available and when the country is reasonably open to international trade (as documented in Sachs and Warner, 1995). The time period is sufficiently long to make reasonable the assumption of capital mobility within and across sectors at the national level.

Labor To measure the quantity of labor in a given industry and at the manufacturing level, we use data from the UNIDO database. These data are corrected for the heterogeneity of human capital with the method proposed by Hall and Jones (1999) and used, for instance, by Debaere and Demiroglu (2003, 2006). Data on educational achievement are from Barro and Lee (2000). Table 2 contains the relevant data.

Capital To compute the stocks of capital at the industry level, we use investment data from the UNIDO at the 3-digit (UNIDO, 2005a) and 4-digit (UNIDO, 2005b) levels. ${ }^{15}$ We take investment in current U.S. dollars, and use exchange rates from the PWT to translate these numbers

\footnotetext{
${ }^{15}$ Investment corresponds to the purchases and own-account construction of fixed assets, including land, buildings, other construction and land improvements, transport equipment, a well as machinery and other
} 
in the current national currency. We compute the implicit national investment deflators as the ratio value of national investment in current national currency units (ICUR) / value of national investment in 1996 national constant prices (IKON). With the deflated investments, we then use the perpetual inventory method to compute stocks of capital at the sectoral level. We choose a depreciation rate of $6 \% .{ }^{16}$ The exact formula is the one employed by Leamer $(1984, \mathrm{p}$. 233, third proposed method). We compute initial capital stocks assuming a constant geometric growth rate for investment. This way we obtain national stocks of capital in the 1996 national currency units.

In this paper as in all works with international cross sections involving quantities of factors, one of the main difficulties is to build data that are comparable across countries. This is especially true for the stocks of capital (Leamer, 1984). Using only the 1996 exchange rates relative to the U.S. dollar to obtain stocks of capital in 1996 U.S. dollars might be misleading for the one willing to have capital stocks comparable across countries. One approach, since Trefler (1993), is to correct for the heterogeneity in the productivity of capital. The work by Trefler (1993) is usually interpreted as indicating a strong correlation between the purchasing power parity-adjusted price of investment goods (as measured by the PWT) and their productivity. Following these results, Debaere and Demiroglu $(2003,2006)$ use the price of investment goods given in the PWT as a measure of capital productivity. The idea is that a higher price indicates a higher quality, poorly measured by the PWT. With this method, measured investment is equipment. The stocks of capital we measure therefore include part (land) of what Caselli and Feyrer (2007) call the non-reproducible capital. Other natural resources are omitted, but the impact of this omission is mitigated by the fact that we focus on the manufacturing sector. The first database provides data for the period 1963-2001, and the second database covers the period 1985-2001. The second database contains data missing in the first one. We merge the two matrices. Even after merger, the database contains many holes. In order to compute stocks of capital, we had to make assumptions about these missing values. When there are holes within a sequence and when there are less than 6 consecutive years of missing data, we complete the sequence using a linear interpolation. When the beginning (end) of a sequence is missing, we replace the last (first) three missing values with an average of the first (last) three available values. Finally, we keep capital stock estimates only when we have at least 8 consecutive years of investment data (once holes are filled).

${ }^{16}$ This is the discount rate chosen by Caselli (2004). When we choose higher discount rates (like $10 \%$ ), the results remain qualitatively unaffected, but the financial rates of return to capital estimated later seem unreasonably high. 
adjusted upward when investment is reported to be costly.

Instead, we think it is more natural to rely on Eaton and Kortum (2001) to derive estimates of the relative prices of quality-equivalent capital in the various countries. They use 1985 data on the international trade of equipment goods ${ }^{17}$ to infer their real prices in many developed and developing countries. The ability to extract information on relative prices from trade data is based on the following reasoning: 1) observing country $n$ with big market shares around the world indicates that $n$ is a competitive supplier of capital goods, and 2) observing that country $n^{\prime}$ imports a lot relative to home purchases indicates that $n^{\prime}$ does not face costly trade barriers to imported capital goods. Eaton and Kortum (2001) find that trade barriers are high for the less developed countries: given the fact that they do not export equipment goods, imports of capital goods should represent a higher fraction of their investment. Among these barriers to trade (also including geographical distance from the major exporters of equipment goods), a low level of skills in poor countries appears to be especially important. This can be interpreted as follows: in relatively backward economies, firms with a low-skilled labor force cannot use the high quality equipment goods produced in the most advanced economies (these goods are not "appropriate"), and, as a result, these goods are not imported; international differences in educational levels therefore result in international quality differences for capital goods. The Eaton-Kortum (2001) estimates for the price of equipment goods for a given country can be understood as the real price of a quality-equivalent unit of equipment good. As prices are normalized so that the U.S. price is equal to one, we find for each country a proxy for the quality-equivalent investment in capital goods (relative to the USA) by adjusting investment by the reported prices for equipment goods. ${ }^{18}$ We therefore use the measured price

\footnotetext{
${ }^{17}$ Electrical machinery, nonelectrical machinery, and instruments.

${ }^{18}$ More precisely, Eaton and Kortum (2001) conduct a structural estimation of the national prices of (qualityequivalent units of) equipment goods. Their empirical model is a Ricardian model with barriers to trade and a continuum of heterogeneous goods. They estimate the costs parameters that are consistent with their model and with observed bilateral trade data. Their theoretical approach and ours are notably different. But we can still have a situation in which 1) the producer (selling) prices of similar capital goods are almost the same in all countries (as assumed here), and, 2) due to barriers to trade (transportation costs and differences in skills),
} 
of equipment capital to adjust reported investment downward when investment is costly. ${ }^{19}$ To obtain a quality-equivalent stock of capital, we simply divide investment by the price of qualityequivalent capital as estimated by Eaton and Kortum (2001).

Ideally, we should use price estimates for each year, rather than the Eaton-Kortum's (2001) estimates for 1985. Nevertheless we think that this measure is appropriate for a vast majority of countries as international differences in the real cost of capital should be persistent over time. If international differences in the price of quality-equivalent capital are due to trade barriers like physical distance and the lack of education, these differences should remain pretty stable over time. Indeed, even though the geographical distribution of equipment goods production has slightly changed over time, most countries far away from the main producers of equipment goods have not seen this distance going down over time. And, similarly, the educational gap between the USA and the other countries has not changed much since the beginning of the period we study. ${ }^{20}$

\section{$<$ Table 2 here. $>$ \\ $<$ Figure 7 here. $>$}

With these data, we can check that labor in each country $n$ is approximately distributed uniformly in industries with capital-labor ratios in an interval of the form $\left[\frac{K_{n}^{* t}}{L_{n}^{* t}} \frac{2 \tau_{1}}{\tau_{1}+\tau_{2}} ; \frac{K_{n}^{* t}}{L_{n}^{* t}} \frac{2 \tau_{2}}{\tau_{1}+\tau_{2}}\right]$. As we have chosen $\tau_{1}=1,500$ and $\tau_{2}=15,000$, labor in country $n$ should be distributed uniformly in industries with capital-labor ratios in $\left[\frac{K_{n}^{* t}}{L_{n}^{* t}} \frac{2 \times 1,500}{1,500+15,000} ; \frac{K_{n}^{* t}}{L_{n}^{* t}} \frac{2 \times 15,000}{1,500+15,000}\right]=\left[0.18 \frac{K_{n}^{* t}}{L_{n}^{* t}} ; 1.82 \frac{K_{n}^{* t}}{L_{n}^{* t}}\right]$. Figure 7 plots the empirical cumulative distribution function (cdf) of labor across industries.

the effective prices of quality-equivalent units of capital goods do differ across countries.

${ }^{19}$ Eaton-Kortum (2001) document that there is a strong negative relationship between the price of equipment goods and the real GDP per capita. When estimating the relationship, we find $P_{k n}=4.53_{(0.41)}-$ $0.70_{(0.12)} \ln \left(y_{n}^{1985}\right)$, where $y_{n}^{1985}$ is country $n$ 's real GDP per capita relative to the US in 1985 (100 for the USA). Standard errors are reported in parentheses. The $R^{2}$ is equal to 0.54 . When a price estimate is missing in EatonKortum (2001), we get an estimate of the missing price by using this relationship. We then use $z_{K n}=1 / P_{k n}$ for all countries.

${ }^{20}$ Countries like Korea and Norway are exceptions. For these countries we tend to underestimate real investment for the years after 1985. This is in part compensated by an overestimation for years before 1985 . 
We have normalized the industry capital-labor ratios by the same ratio at the country level (in the manufacturing sector), $\frac{K_{n}^{* t}}{L_{n}^{* t}}$. If our assumption is right, each cdf should be on the thick line. Figure 7 indicates that our assumption comes close to what really happens in reality. ${ }^{21}$ We do find that more than $90 \%$ of labor is employed in industries within the required range. There are also some significant industries with capital-labor ratios clearly higher than $\frac{K_{n}^{* t}}{L_{n}^{* t}} \frac{2 \tau_{2}}{\tau_{1}+\tau_{2}}$. Unsurprisingly, these are the steel and chemicals industries.

Correcting for the quality differences for the two factors has a significant impact on the relative capital-labor ratios: Table 2 reveals that the correction factor for capital is the most important. As a result, the relative capital-labor ratio for the typical less developed country shrinks.

For the various periods we study, Table 3 presents the average capital-labor ratios at the industry level in a rich country (the USA) and in a developing one (Malaysia). It appears that the industries which are the most labor-intensive in the USA are also the most labor-intensive in Malaysia (like Footwear or Furniture). But, with our classification in two HO aggregates and an industry cutoff at $q=3,000$, we find that, for the USA, just the wearing apparel industry in 1976-1980, is considered to be labor-intensive. On the contrary, for Malaysia in the period 1976-1980, 8 industries (out of 19) belong to the labor-intensive HO aggregate. We also obtain the possibly counterintuitive result that the U.S. textile industry was capital-intensive in 1976-1980, while, during the same period, the transport equipment industry in Malaysia was labor-intensive. This result is counterintuitive because, in OECD countries, the transport equipment industry is more capital-intensive than the textile industry. Table 3 just indicates that, due to within-industry specialization (and possibly factor substitution), the transport equipment industry in Malaysia is more labor-intensive than the textile industry in the USA.

\footnotetext{
${ }^{21}$ The shape of the cdf might indicate that capital intensities actually follow a gamma distribution. In this paper, we keep the uniform distribution for its simplicity.
} 
$<$ Table 3 here. $>$

Value-added We compute value-added in 1996 U.S. dollars using the 1996 exchange rates and national consumption deflators implicitly given by the PWT. We prefer not to use PPP-adjusted values: as in the $\mathrm{HO}$ model, we assume that all goods produced with the same capital-labor ratio can be sold at the same price on international markets. We conjecture that, for tradables, the observed deviations from absolute PPP at the retail level can be well explained by differences in distribution costs across countries. ${ }^{22}$ Thus, we do not assume that the law of one price holds at the retail level, but we assume that it holds at the producer level.

Ireland appears to be a very specific country: its industry is characterized by an extremely rapid growth in value-added per worker and a rather slow growth in capital per worker; growth of the Irish industry cannot be explained by our HO model. As a result, we exclude Ireland from our baseline regression and then discuss the results we obtain when this country is included.

\subsection{Estimation of the model: results}

Table 4 presents the results of our estimation for the cutoffs $\tau_{1}=1,500, \tau_{2}=15,000$, and $q=3,000$ (all numbers in 1996 U.S. dollars of quality-equivalent capital per effective worker). The period dummies appear to be small (especially for the capital-intensive aggregate) and/or not statistically significant (especially for the labor-intensive aggregate). This indicates that, over the 1976-2000 period, production patterns across countries are consistent with the model with fixed (relative) prices and technologies. We interpret these findings as a validation of our hypothesis that the cone cutoffs have not moved much between 1976 and 2000 .

Our results also indicate a large drop in the value of the return to capital when moving from the very labor-rich cone to the cone of diversification (with $\hat{\alpha}=0.14$ ). This jump is implied by

\footnotetext{
${ }^{22}$ Distribution services (local land and labor) are mostly nontradable, and can therefore differ importantly across countries. As these distribution costs account for $50 \%$ of the retail prices (Burstein et al., 2003), differences in distribution prices can generate huge differences in retail prices.
} 
our simplifying linearity assumption for the first cone and the decrease of the return to capital would be smoother with a Cobb-Douglas specification in the first cone. But, even with this other specification, we would measure a rapid decrease of the return to capital when countries start accumulating capital. The labor elasticity of output is found to be of the right order of magnitude $(\hat{\beta}=0.46)$. It may look small, but one should not forget that this elasticity is by assumption common to all countries, including the low- or mid-income ones where the labor share of income in manufacturing is lower than in rich countries.

$<$ Table 4 here.>

For the 44 countries included in the regression, Figures 8-13 present the actual development paths (with filled squares and circles) and the fitted/predicted development paths (with solid and dashed curves), setting the time dummies at 0, i.e. we report,

$$
V A_{k n}^{t, p r e d} / L_{n}^{* t}=\hat{r}_{1 n} f_{k}\left(K_{n}^{* t} / L_{n}^{* t}, \tau_{1}, \tau_{2}, \hat{\alpha}, \hat{\beta}\right)
$$

and

$$
V A_{l n}^{t, p r e d} / L_{n}^{* t}=\hat{r}_{1 n} f_{l}\left(K_{n}^{* t} / L_{n}^{* t}, \tau_{1}, \tau_{2}, \hat{\alpha}\right)
$$

Figures 8-13 therefore show the changes in specialization due to the Rybczynski effect. They also show the predicted changes in specialization if countries were to accumulate even more capital, assuming a strong persistence in price and TFP levels. The figures indicate that, over the whole period, the share of the labor-intensive aggregate in global production has been small. Many countries are specialized in the production of capital-intensive goods. But countries like Bulgaria, Egypt, Indonesia, Malaysia and Sri Lanka produce significant quantities of the laborintensive aggregate and exhibit specialization patterns that are consistent with our empirical model.

$<$ Figure 8 here. $>$ 
$<$ Figure 9 here. $>$

$<$ Figure 10 here. $>$

$<$ Figure 11 here. $>$

$<$ Figure 12 here. $>$

$<$ Figure 13 here. $>$

In a related work, Xu (2003) focuses on 14 developing countries during the period 19821992 and runs Rybczynski regressions at the industry level. He also presents evidence that these developing countries were belonging to different cones during the period under consideration. But he finds that developing countries tend to specialize in labor-intensive goods when they accumulate capital. This seems to contradict the textbook Rybczynski prediction. Contrary to $\mathrm{Xu}$ (2003), we find that the Rybczynski effect explains changes in specialization, even for the developing countries. Why such a difference? While Xu (2003) defines the capital-intensity of an industry as the average capital-intensity during the whole period and across all countries, we rather follow Schott (2003) and rely on HO aggregates. This explicitly takes into account the fact that there are substantial differences in capital intensity within industries and that countries alter their intra-industry specialization as they accumulate capital. What we present in this paper is therefore a test of the $\mathrm{HO}$ model that is both less restrictive and more in the spirit of the textbook model. It is less restrictive because we are agnostic about the evolution of industrial specialization if one defines industries as in the ISIC. It is more in the spirit of the HO model as goods are grouped according to their production technology.

One way to check whether our results make sense or not is to compute the annual compensations implied by our estimates: for each country and at any point in time, the implied annual compensation for an effective unit of labor is given by the intercept of the vertical axis and the tangent to the total value-added curve. Data on compensation in the manufacturing sector are collected by the International Labor Organization. ${ }^{23}$ Figure 14 presents these actual compensa-

\footnotetext{
${ }^{23}$ See the International Labor Organization website, http://laborsta.ilo.org. Annual compensation data are
} 
tions in 1996 and the compensations implied by our model. The implied compensations appear to be of the right order of magnitude. For the United States and Japan, we have an almost perfect prediction. But for other countries, the implied compensation is significantly different from the actual one: for many South or Central American countries, we overestimate compensation, while for the European countries, compensation is underestimated. We nevertheless find that the overall results strengthen the case for the "HO aggregates" approach.

$<$ Figure 14 here. $>$

\subsection{Robustness checks}

Including Ireland changes the results in an anticipated way. In Ireland, value-added per worker has increased dramatically and this rapid rise has not been matched by any corresponding increase in the capital-labor ratio. In addition, Ireland is rather specialized in the capitalintensive HO aggregate. As a result, when we include Ireland, $\delta_{k}^{t}$ rises with $t$ (from 0 for $t=1978$ to 0.18 for $t=1998$ ), as well as $\delta_{k}^{t} / \delta_{l}^{t}$. This indicates that, everything else equal, countries should alter their specialization towards the capital-intensive goods. Similarly, the cone cutoffs should move over time, which contradicts our assumption of fixed cutoffs. Nevertheless, as Ireland remains a medium-size economy, we consider the estimates without Ireland as our main results.

We have presented results with specific cone cutoffs, $\tau_{1}=1,500$ and $\tau_{2}=15,000$, and a corresponding HO aggregate cutoff, $q=3,000$ (all numbers in 1996 U.S. dollars of qualityequivalent capital per effective worker). With lower $\tau_{c}$ 's and adjusting accordingly the HO aggregate cutoff, $q$, the results are not much affected. For instance, we cannot reject that $\delta_{k}^{t}=\delta_{l}^{t}$ over the whole period, 1976-2000. With $\tau_{1}=2,000, \tau_{2}=15,000$ and $q=4,000$, we

not always available for 1996. When this is not the case, we use other compensation data (monthly, weekly, daily, hourly) or wage data. When used, wage data are multiplied by 1.5. The U.S. compensation data have been multiplied by 1.2 as the available data are for production workers only. For Denmark, we used 1993 compensation data. When the 1996-2000 capital-labor ratio is not available for a country, we use the most recent available number. 
cannot reject this hypothesis over the whole period (except for the period 1993-1997). With the latter cutoffs, we still find very small positive change in the absolute profitability of producing the capital-intensive goods (little changes in $\delta_{k}^{t}$ ), while the results might indicate a decrease in the relative price of labor-intensive goods.

We have also estimated a model without decreasing marginal product of capital in the capital-rich cone. Most of the results do not change significantly. The major change occurs for the implied compensations. As expected, we find lower implied compensations for the countries in the third cone, and the gap between the implied compensations and the actual ones gets larger. The overall fit of the model (measured by the root MSE for the two aggregates) gets also reduced. We take this as evidence in favor of a decreasing return to capital in the third cone. An estimation of the model setting $\beta=0.6$ indicates a slightly higher increase in the profitability of producing the capital-intensive goods, but we still cannot reject that $\delta_{k}^{t}=\delta_{l}^{t}$ over the whole period.

\section{The return to capital}

\subsection{The financial rate of return to capital}

The HO model with more than one cone predicts that the return to capital is constant in the diversification cone(s), decreasing with the capital-labor ratio in the specialization cones, and decreasing from one cone to the next. In the present work, because the return to capital (or the value of the MPK) is the slope of the total value-added per worker curve and because prices are expressed in 1996 U.S. dollars, we can find an estimate of the return to capital in country $n$ in 1996-2000 implied by our model. It is given by: 


$$
\begin{aligned}
\widehat{r}_{n} & =\hat{r}_{1 n} \text { if } \frac{K_{n}^{*}}{L_{n}^{*}} \leq \tau_{1} \\
& \left.\left.=\hat{\alpha} \hat{r}_{1 n} \text { if } \frac{K_{n}^{*}}{L_{n}^{*}} \in\right] \tau_{1} ; \tau_{2}\right] \\
& =\hat{\alpha} \hat{r}_{1 n} \tau_{2}^{\hat{\beta}}\left(\frac{K_{n}^{*}}{L_{n}^{*}}\right)^{-\hat{\beta}} \text { if } \frac{K_{n}^{*}}{L_{n}^{*}}>\tau_{2},
\end{aligned}
$$

where $\frac{K_{n}^{*}}{L_{n}^{*}}$ is the average capital-labor ratio in country $n$ during the period 1996-2000. Note that these are the returns to a unit of quality-equivalent capital in the various countries. Imposing the structure of our empirical model should allow to get rid of some biases introduced by measurement errors or medium-run fluctuations. Table 5 (first column) shows the resulting estimates for the return to capital in the various countries. ${ }^{24}$

$<$ Table 5 here. $>$

Figure 15 makes clear that, as predicted by the HO model with multiple cones, the value of $\widehat{r}$ is decreasing with $\frac{K^{*}}{L^{*}}$. The correlation between the capital-labor ratio and $\widehat{r}$ is $-0.24 .^{25}$

As presented in Caselli and Feyrer (2007), in a world of capital mobility in which firms and households have access to investment opportunities that yield a common world interest rate $R^{*}$, what should be equalized is the financial return of investing in the manufacturing sector in the various countries. So, for each country $n$, we should have an equality between the gross rate of return (of investing in the country's manufacturing sector) and a common gross rate of return $R^{*}$ :

$$
\frac{r_{n}(t)+P_{k n}(t+1)(1-d)}{P_{k n}(t)}=R^{*}, \forall n
$$

\footnotetext{
${ }^{24}$ As Sri Lanka had an average capita-labor ratio just below the cone cutoff $\tau_{1}$ during the period 1996-2000, we use Equation 15 to compute its return to capital.

${ }^{25} \mathrm{In}$ a linear regression of $r$ on $K^{*} / L^{*}$, the coefficient on $K^{*} / L^{*}$ is negative, but not statistically different from zero at conventional levels, perhaps due to our small sample size. Although Bangladesh appears to be a country with a very high return to capital, our results do not change much when excluding this country from our sample.
} 
where $d$ is the depreciation rate. Assuming that the price of capital goods remains constant over time in each country, we would expect the financial rates of return to capital to be equalized:

$$
F R R K_{n}=\frac{r_{n}}{P_{k n}}-d=R^{*}-1, \forall n
$$

In this world, it is the return to capital (or the value of the MPK) corrected by the real price of capital goods that should be similar across countries. Table 6 (second column) reports our estimates of the financial rates of return to capital for the year 1996. These are generally much lower and less dispersed than the original $r_{n}$ 's. Figure 15 plots $\widehat{F R R K}_{n}=\frac{\widehat{r}_{n}}{P_{k n}}-d$ as a function of $K_{n}^{*} / L_{n}^{*}$. It clearly shows that the returns to capital are indeed made much more equal by this real price adjustment. On average, a higher $\frac{K^{*}}{L^{*}}$ does not imply a lower financial rate of return to capital. The correlation between the capital-labor ratio and $\widehat{F R R K}$ is almost equal to 0 , at $0.06 .{ }^{26}$ This evidence can be taken as part of an explanation for the Lucas (1990) paradox. Indeed, there does not seem to be much to be gained from a systematic reallocation of capital from rich to poor countries.

\section{$<$ Figure 15 here. $>$}

These findings bear some similarity with those of Caselli and Feyrer (2007). With a different estimation method, they also find that the physical MPK is much higher on average in poor countries. Relying on data from the PWT, they argue that this is compensated by a relatively high cost of investment goods in these countries. Contrary to our reasoning, they argue that this high relative cost of capital goods in poor countries is due to a low price of consumption goods in those countries, while capital goods sell at roughly the same price in all countries. As noticed by Caselli and Feyrer, this may be a consequence of the Balassa-Samuelson hypothesis

\footnotetext{
${ }^{26}$ In a linear regression of $F R R K$ on $K^{*} / L^{*}$, the coefficient on $K^{*} / L^{*}$ is positive, but not statistically different from zero. When we exclude Bangladesh, the same coefficient is still positive and becomes statistically significant.
} 
(the productivity gap between poor and rich countries is larger for tradables (including capital goods) than for non-tradables (including consumption goods)) ${ }^{27}$

In this paper, we also find that the returns to capital tend to be higher in poor countries and that these differences are compensated by a high relative cost of capital goods in poor countries. But, on the last point, our reasoning is the opposite of the one by Caselli and Feyrer (2007). As we focus on the manufacturing sector, the produced goods are generally tradable and therefore the law of one price should be approximately valid for these goods. On the contrary, we use the results in Eaton-Kortum (2001) who find that a unit of quality-equivalent capital is more expensive in poor countries. We thus find in poor countries a high relative price of capital goods, but this is due to their high absolute prices.

\subsection{The return to capital and structural change}

Neoclassical growth theory does not predict that, in autarky, capital accumulation should fundamentally alter the structure of the economy. An increase in the capital-labor ratio leads to a reduction in the relative cost of capital and industries substitute capital for labor accordingly. With more capital-intensive techniques, the marginal product of capital goes down and growth rates of autarky economies are bound to converge.

Ventura (1997) proposes a mechanism through which international trade favors capital accumulation, structural change and growth. A small open economy that accumulates capital moves its resources away from the labor-intensive industries to the capital-intensive industries. This is the Rybczynski effect. Note that this is possible as long as the country is not fully specialized in the capital-intensive goods. But this structural transformation raises the demand for capital and helps to sustain the marginal product of capital. As long as the world capital-labor ratio does not change, the relative price of the capital-intensive goods and the value of the marginal

\footnotetext{
${ }^{27}$ Hsieh and Klenow (2007) provide empirical evidence for this hypothesis.
} 
product of capital remain stable. By trading with the rest of the world, the growing economy "beats the curse of diminishing returns". Ventura (1997) argues that this phenomenon is part of the explanation for the economic "miracle" in East Asia.

Our results support this analysis, but they allow us to be more precise about the actual process. In his model, Ventura (1997) assumes that all countries are in the same cone, necessarily a cone of diversification. On the one hand, we have found instead that most countries move within or across two cones. On the other hand, we show two things that might generate what Ventura exposes.

First, we find almost by construction that, during the first phase of their miracle, the East Asian countries remained in the cone of diversification. If Ventura's (1997) reasoning can be transposed to our world with not two goods but with two HO aggregates, the MPK must have been constant over time for the East Asian countries, at least in the first phase of their miracle.

Second, our results indicate that the return to capital has not decreased over time at any given capital-labor ratio. This happened even though most countries accumulated capital, and not only the (initially) small East Asian economies. To explain this result, we can mention that labor-rich countries have started trading with the rest of the world, thus stabilizing the world capital-labor ratio. It might also be that returns to capital have been sustained by technological progress in the capital-intensive industries. Finally, the result may be due to a non-homothetic demand. The important result is that some economic mechanisms have sustained the value of the MPK.

In addition, the data tell us that changes in intra-industry specialization have also been significant during the period 1976-2000. This possibility to alter one's specialization within an industry should facilitate the process of factor reallocation. Intuitively, it should be easier for firms to alter their specialization from, say, rudimentary machinery to higher quality machinery (a change in intra-industry specialization) than from coarse textiles to high quality machinery 
(a change of specialization across industries). ${ }^{28}$ What are the respective contributions of intraindustry specialization and between-industry specialization to the change in $K / L$ ? This can be found using the decomposition that follows. A country's capital-labor ratio at date $t$ is just the weighted sum of the capital-labor ratios in the various industries, the weight of industry $i$ being its labor share:

$$
\frac{K_{n}^{* t}}{L_{n}^{* t}}=\frac{\sum_{i=1}^{I} K_{i n}^{* t}}{\sum_{i=1}^{I} L_{i n}^{* t}}=\sum_{i=1}^{I} s_{i n}^{t} \frac{K_{i n}^{* t}}{L_{i n}^{* t}}
$$

with $s_{i n}^{t}=\frac{L_{i n}^{* t}}{\sum_{i=1}^{l} L_{i n}^{* t}}$. The change in a country capital-labor ratio can then be decomposed as the combination of two effects:

$$
\Delta\left(\frac{K_{n}^{*}}{L_{n}^{*}}\right)^{t, t+1} \equiv \frac{K_{n}^{*, t+1}}{L_{n}^{*, t+1}}-\frac{K_{n}^{* t}}{L_{n}^{* t}}=\underbrace{\sum_{i=1}^{I} s_{i n}\left(\frac{K_{i n}^{*, t+1}}{L_{i n}^{*, t+1}}-\frac{K_{i n}^{* t}}{L_{i n}^{* t}}\right)}_{\text {within-industry change }}+\underbrace{\sum_{i=1}^{I}\left(s_{i n}^{t+1}-s_{i n}^{t}\right) \frac{K_{i n}^{*}}{L_{i n}^{*}}}_{\text {between-industry change }},
$$

with $s_{i n}=\frac{s_{i n}^{t}+s_{i n}^{t+1}}{2}$ and $\frac{K_{i n}^{*}}{L_{i n}^{*}}=\frac{K_{i n}^{* t} / L_{i n}^{* t}+K_{i n}^{*, t+1} / L_{i n}^{* t+1}}{2}$. A positive within-industry change indicates that, on average, industries have become more capital-intensive: this shows how changes in intra-industry specialization and factor substitution can explain a change in a country's capitallabor ratio. A positive between-industry change indicates that, on average, the labor share of the capital-intensive industries has gone up.

Table 6 presents the results of this decomposition for the periods (1976-1980)-(1986-1990) and (1986-1990)-(1996-2000). The result is striking: for most countries, the within-industry change is by far the most important. This is due to two factors: the standard factor substitution, but also the changes in intra-industry specialization emphasized in Schott (2003) and here. While we do find in the data that, in Korea for instance, labor has massively moved out of the labor-intensive textile industry, this kind of reallocation of labor across sectors remains an exception. In addition, this movement of labor out of the textile industry does not explain

\footnotetext{
${ }^{28}$ With data on the U.S. manufacturing sector, Bernard, Jensen, and Schott (2006) show that changes in specialization within the same industry can also be a response to competition from exporters located in lowwage countries.
} 
much of the increase in the Korean capital-labor ratio in manufacturing because, when compared to the Korean average capital-labor ratio, this sector is not extremely labor-intensive. Moreover, as Xu (2003), we find that some capital-accumulating countries (Singapore for instance) increase their production in the industrial sectors that are on average labor-intensive (negative contribution of the between effect). Table 6 also indicates that a minority of countries (like Chile, Greece, Portugal and Spain) have experienced substantial changes in specialization between industries. Overall, the structural change emphasized by Ventura (1997) should be facilitated by the fact that it occurs mainly within industries rather than between industries.

$<$ Table 6 here. $>$

\section{Conclusion}

Using panel data, we estimate a simple Heckscher-Ohlin (HO) model with multiple cones, intra-industry specialization, and TFP differences across countries. In addition, to make factor quantities comparable across countries, we measure factors in effective quality-equivalent units. With the time dimension, we can improve on Schott (2003) who focused on a single cross section: the country time series allow us to estimate TFP differences and to compare the actual development paths to the ones predicted by theory.

More fundamentally, with our integrated approach, we emphasize not only the relationship between factor endowments and specialization, but also the role played by factor returns. Indeed, with the estimated parameters, we can obtain both the compensations for effective units of labor and the rental rates for effective units of capital implied by the model. We then use these estimates to test for the internal consistency of the approach (there is no FPE) and to study the incentives to re-allocate or accumulate capital.

We confirm the traditional Heckscher-Ohlin prediction that if factor endowments are sufficiently far away, regions may produce sufficiently different goods so that they are not directly 
competing. One should, however, consider the recent contributions of Schott (2008) and Hallak and Schott (2009), who emphasize the importance of differences in the quality of goods, as qimportnat qualifiers to any policy implications that one could wish to draw from our results.

In the various cross sections, we find that poor countries have higher rental rates of capital and, accordingly, specialize in the production of labor-intensive goods. Although one could expect these higher returns to attract investment from rich countries, we show that the financial rates of return to capital investment are generally not higher in the less developed countries. The reason for this is that, as shown by Eaton and Kortum (2001), the price of effective capital is higher in poor countries. This could explain why we do not observe larger investments from rich into poor countries.

Analyzing the development paths, we find that countries experience the structural change predicted by theory. Moreover, decomposing the changes over time in the countries' capitallabor ratios in within-industry changes and between-industry changes, we show that, for most countries (including the East Asian growth miracles), this process of structural change is mainly a change of specialization within industries. Therefore, structural transformation has been less disruptive than it would have been with the more radical changes of specialization across industries. In addition, despite capital accumulation by most countries, we find no decrease in the return to capital (or in the value of the MPK) at any given capital-labor ratio. This must have stimulated growth through capital accumulation. 


\section{References}

Bernard, Andrew B., J. Bradford Jensen, and Peter K. Schott, 2006, "Survival of the best fit: exposure to low-wage countries and the (uneven) growth of US manufacturing plants," Journal of International Economics, 68(1), pp. 219-237.

Bernard, Andrew B., Stephen J. Redding, and Peter K. Schott, 2009, "Testing for Factor Price Equality in the Presence of Unobserved Factor Quality Differences," Working Paper, Yale University.

Bernstein, Jeffrey R., and David E. Weinstein, 2002, "Do endowments predict the location of production? Evidence from national and international data," Journal of International Economics, 56(1), pp. 55-76.

Barro, Robert J., and Jong-Wha Lee, 2001, "International Data on Educational Attainment: Updates and Implications", Oxford Economic Papers, 53(3), pp. 541-563.

Burstein, Ariel, Joao Neves, and Sergio Rebelo, 2003, "Distribution costs and real exchange rate dynamics during exchange-rate-based stabilizations," Journal of Monetary Economics, 50(6), pp. 1189-1214.

Caselli, Francesco, 2004, "Accounting for cross-country income differences," Handbook of Economic Growth, in Philippe Aghion and Steven Durlauf, eds, Elsevier, pp. 679-741.

Caselli, Francesco, and James Feyrer, 2007, "The marginal product of capital," Quarterly Journal of Economics, 122(2), pp. 535-568.

Davis, Donald R., and David E. Weinstein, 2001, "An account of global factor trade," American Economic Review, 91(5), pp. 1426-1454.

Deardorff, Alan V., 1974, "A geometry of growth and trade," Canadian Journal of Economics, $7(2)$, pp. 295-306.

Deardorff, Alan V., 1994, "The possibility of factor price equalization, revisited," Journal of International Economics, 36(1-2), pp. 167-175.

Deardorff, Alan V., 2000, "Patterns of trade and growth across cones," De Economist, 148, pp. 141-166.

Debaere, Peter, and Ufuk Demiroglu, 2003, "On the similarity of country endowments," Journal of International Economics, 59(1), pp.101-136.

Debaere, Peter, and Ufuk Demiroglu, 2006, "Factor accumulation without diminishing returns," 
Review of International Economics, 14(1), pp. 16-29.

Dornbusch, Rudiger, Stanley Fischer, and Paul A. Samuelson, 1980, "Heckscher-Ohlin trade theory with a continuum of goods," Quarterly Journal of Economics, 95(2), pp. 203-224.

Eaton, Jonathan, and Samuel Kortum, 2001, "Trade in capital goods," European Economic Review, 45(7), pp. 1195-1235.

Fitzgerald, Doireann, and Juan Carlos Hallak, 2004, "Specialization, factor accumulation and development," Journal of International Economics, 64(2), pp. 277-302.

Hallak, Juan Carlos, and Peter K. Schott, 2009, "Estimating Cross-Country Differences in Product Quality," Working Paper, Yale University.

Harrigan, James, 1995, "Factor endowments and the international location of production: econometric evidence from the OECD, 1970-1985," Journal of International Economics, 39(12), pp. 123-141.

Harrigan, James, 1997, "Technology, factor supplies, and international specialization: estimating the neoclassical model," American Economic Review, 87(4), pp. 475-494.

Heston, Alan, Robert Summers, and Bettina Aten, 2002, Penn World Table Version 6.1, Center for International Comparisons at the University of Pennsylvania (CICUP), October.

Hsieh, Chang-Tai, and Peter J. Klenow, 2007, "Relative prices and relative prosperity," American Economic Review, 97(3), pp. 562-585.

Kohli, Ulrich R., 1978, "A gross national product function and the derived demand for imports and supply of exports," Canadian Journal of Economics, 11(2), pp. 167-182.

Koren, Miklós, and Silvana Tenreyro, 2007, "Volatility and development," Quarterly Journal of Economics, 122(1), pp. 243-287.

Leamer, Edward E., 1984, Sources of International Comparative Advantage, Cambridge, MA: MIT Press.

Leamer, Edward E., 1987, "Paths of development in the three-factor, n-good general equilibrium model," Journal of Political Economy, 95(5), pp. 961-999.

Lerner, Abba P., 1952, "Factor prices and international trade," Economica, 19(73), pp. 1-15.

Lucas, Robert E., 1990, "Why doesn't capital flow from rich to poor countries?," American Economic Review, 80(2), pp. 92-96. 
Melvin, James R., 1968, "Production and trade with two factors and three goods," American Economic Review, 58(5), pp. 1249-1268.

Redding, Stephen, 2002, "Specialization dynamics," Journal of International Economics, 58(2), pp. 299-334.

Sachs, Jeffrey D., and Andrew Warner, 1995, "Economic reform and the process of global integration," Brookings Papers on Economic Activity, 1, pp. 1-118.

Schott, Peter K., 2001, "One size fits all? Heckscher-Ohlin specialization in global production," working paper 8244, NBER.

Schott, Peter K., 2003, "One size fits all? Heckscher-Ohlin specialization in global production," American Economic Review, 93(2), pp. 686-708.

Schott, Peter K., 2004, "Across-product versus within-product specialization in international trade," Quarterly Journal of Economics, 119(2), pp. 647-678.

Schott, Peter K., 2008, "The relative sophistication of Chinese exports," Economic Policy, 53 (January), pp. 5-49.

Trefler, Daniel, 1993, "International factor prices: Leontief was right!" Journal of Political Economy, 101(6), pp. 961-987.

Trefler, Daniel, 1995, "The case of the missing trade and other mysteries," American Economic Review, 85(5), pp. 1029-1046.

Trefler, Daniel, and Susan Chun Zhu, 2005, "The structure of factor content predictions," working paper 11221, NBER.

United Nations Industrial Development Organization, 2005a, Industrial statistics database, 3digit ISIC, Revision 2, Vienna.

United Nations Industrial Development Organization, 2005b, Industrial statistics database, 3 and 4-digit ISIC, revision 3, Vienna.

Ventura, Jaume, 1997, "Growth and interdependence," Quarterly Journal of Economics, 112(1), pp. $57-84$.

Xu, Bin, 2003, "Capital abundance and developing country production patterns," working paper, University of Florida. 


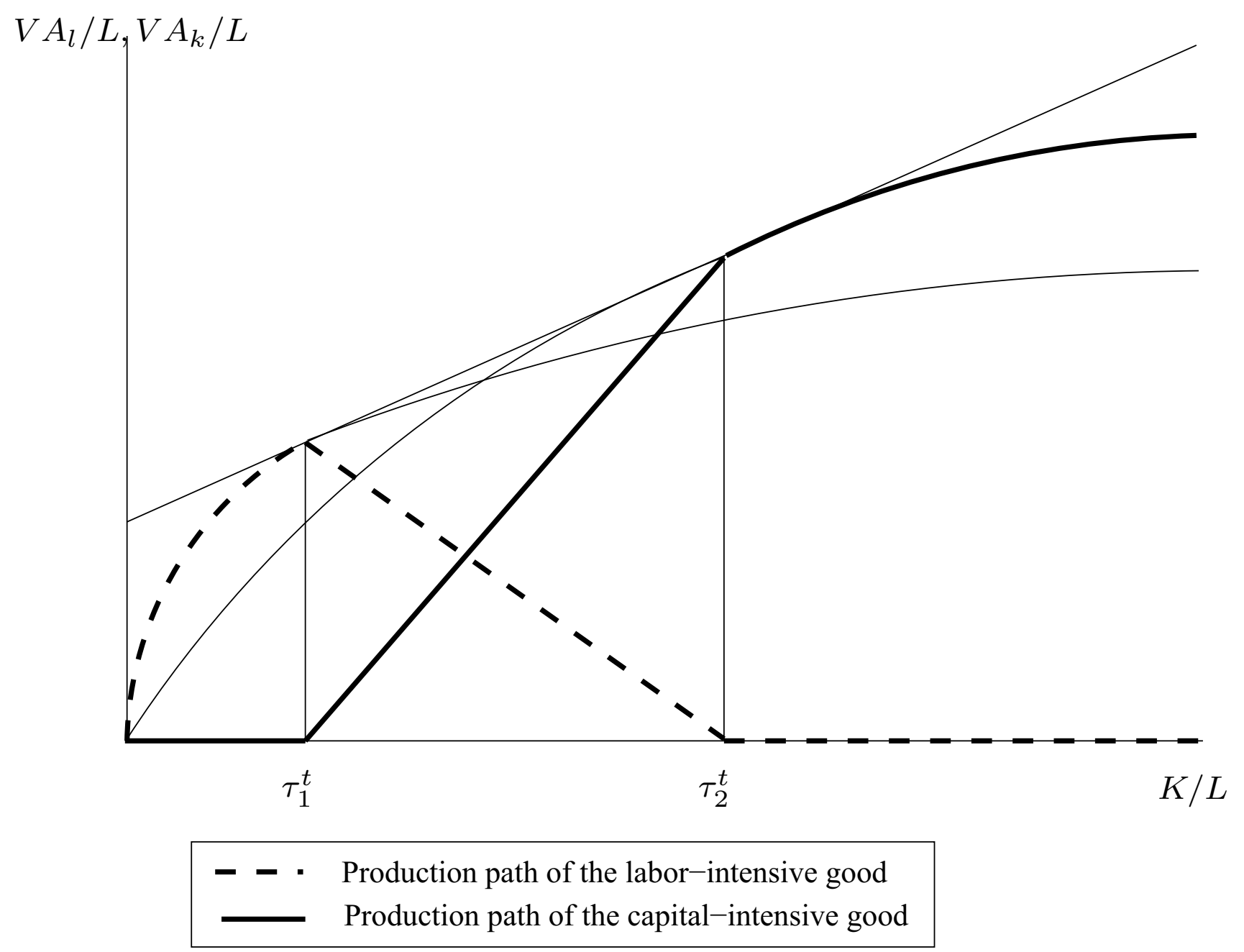

Figure 1: Production patterns in the $2 \times 2 \mathrm{HO}$ model. 


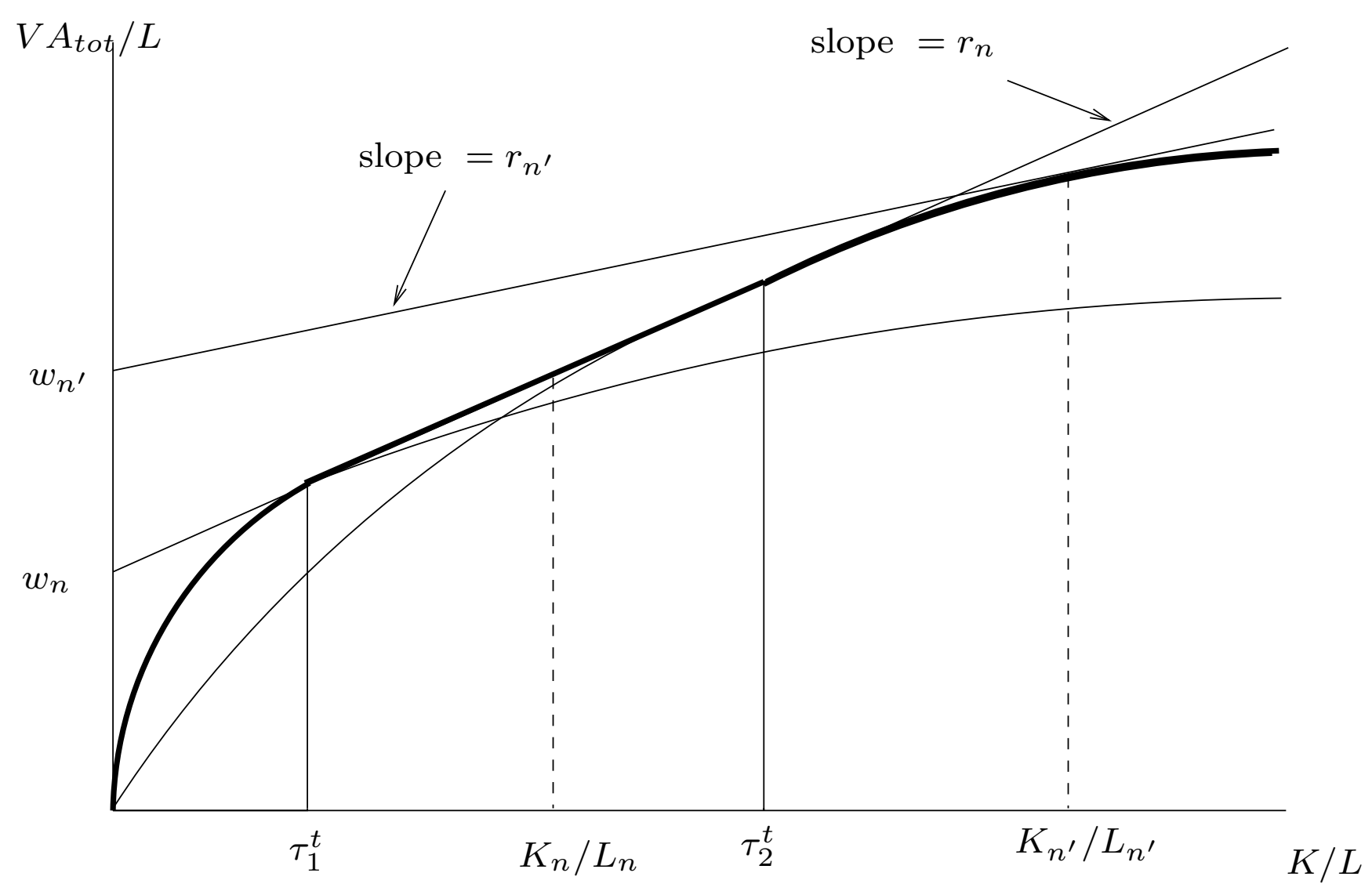

Figure 2: Value-added per worker and factor returns in the $2 \times 2 \mathrm{HO}$ model. 


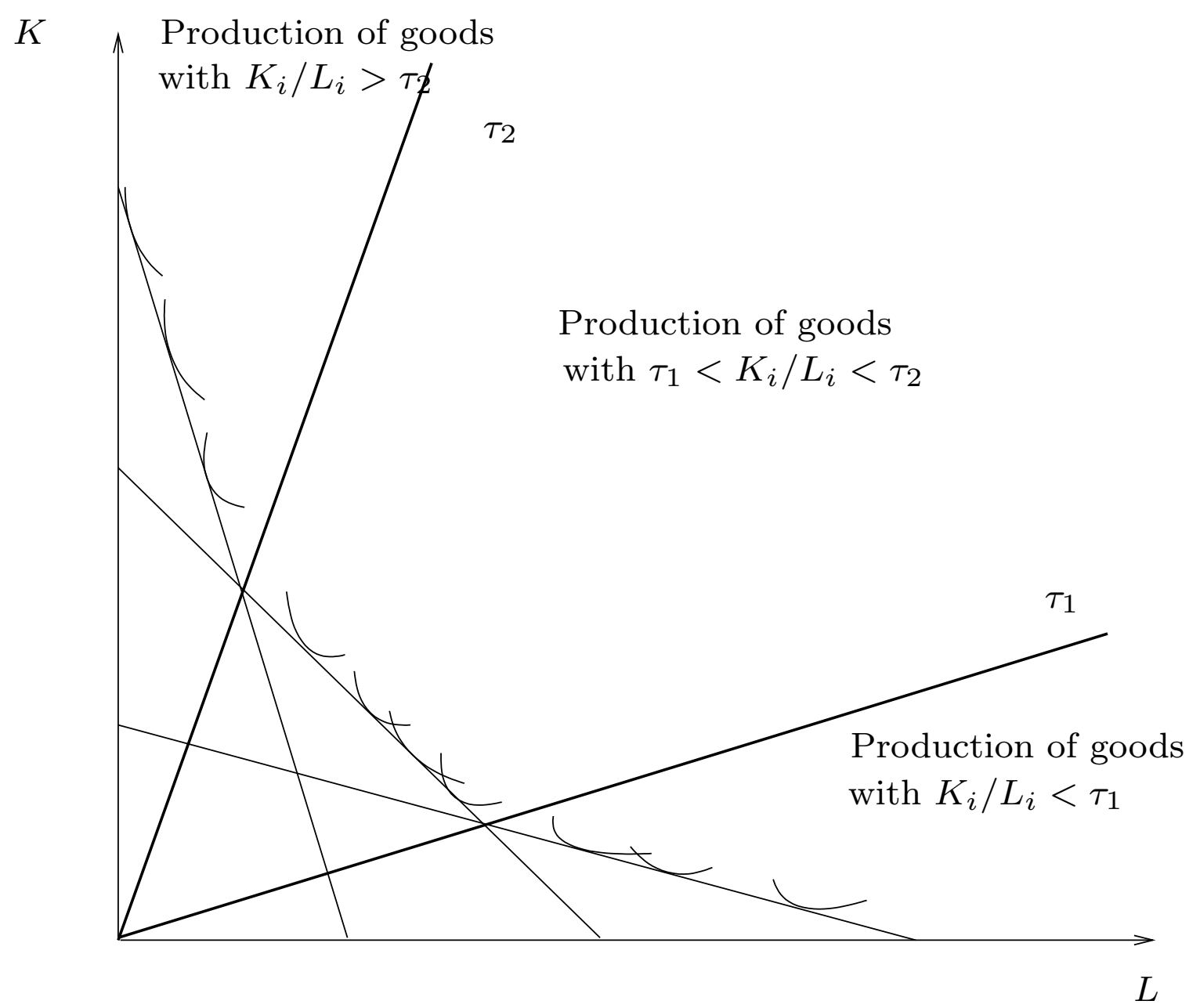

Figure 3: Lerner diagram with three cones of specialization. 


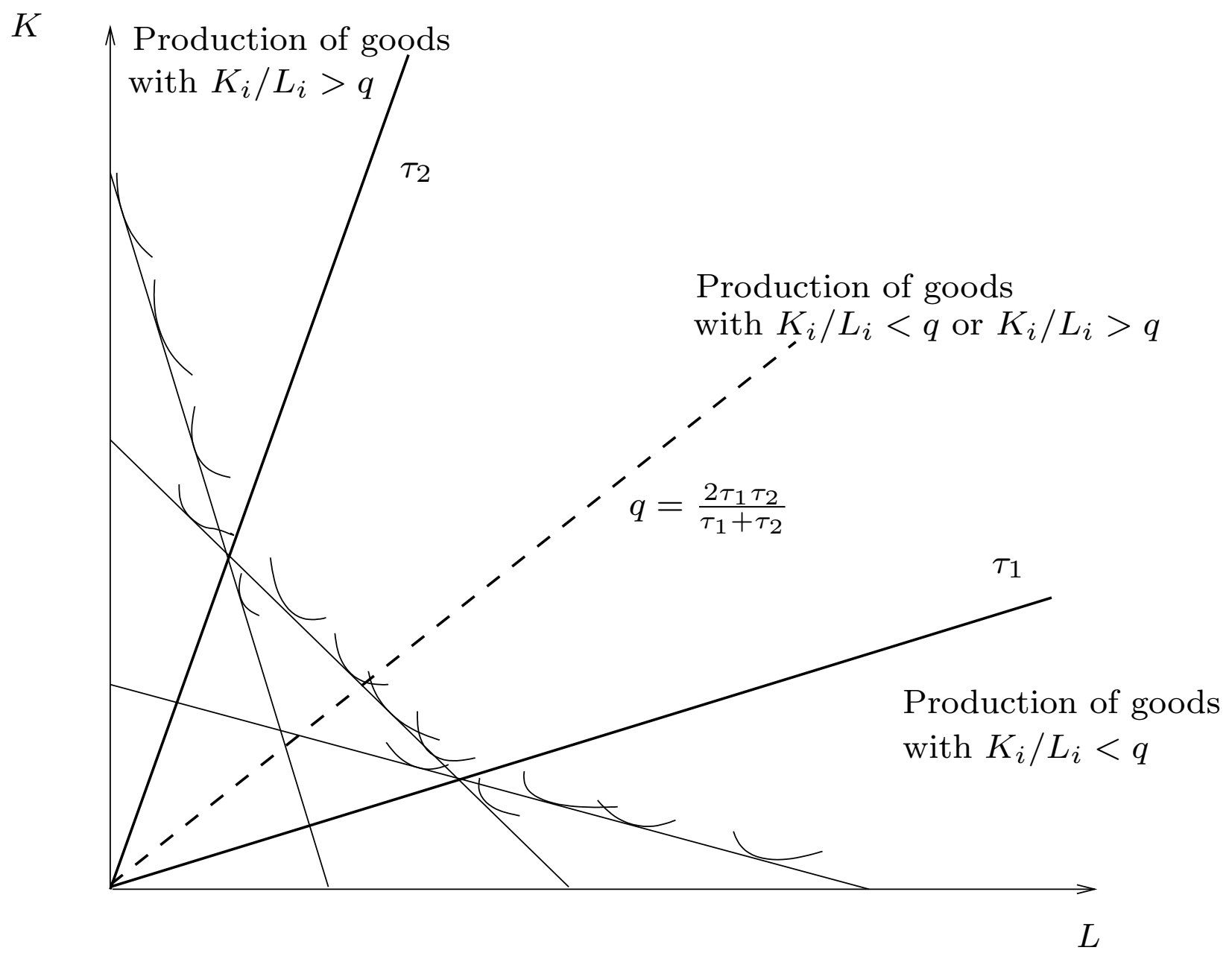

Figure 4: Modified Lerner diagram with three cones and two HO aggregates. 


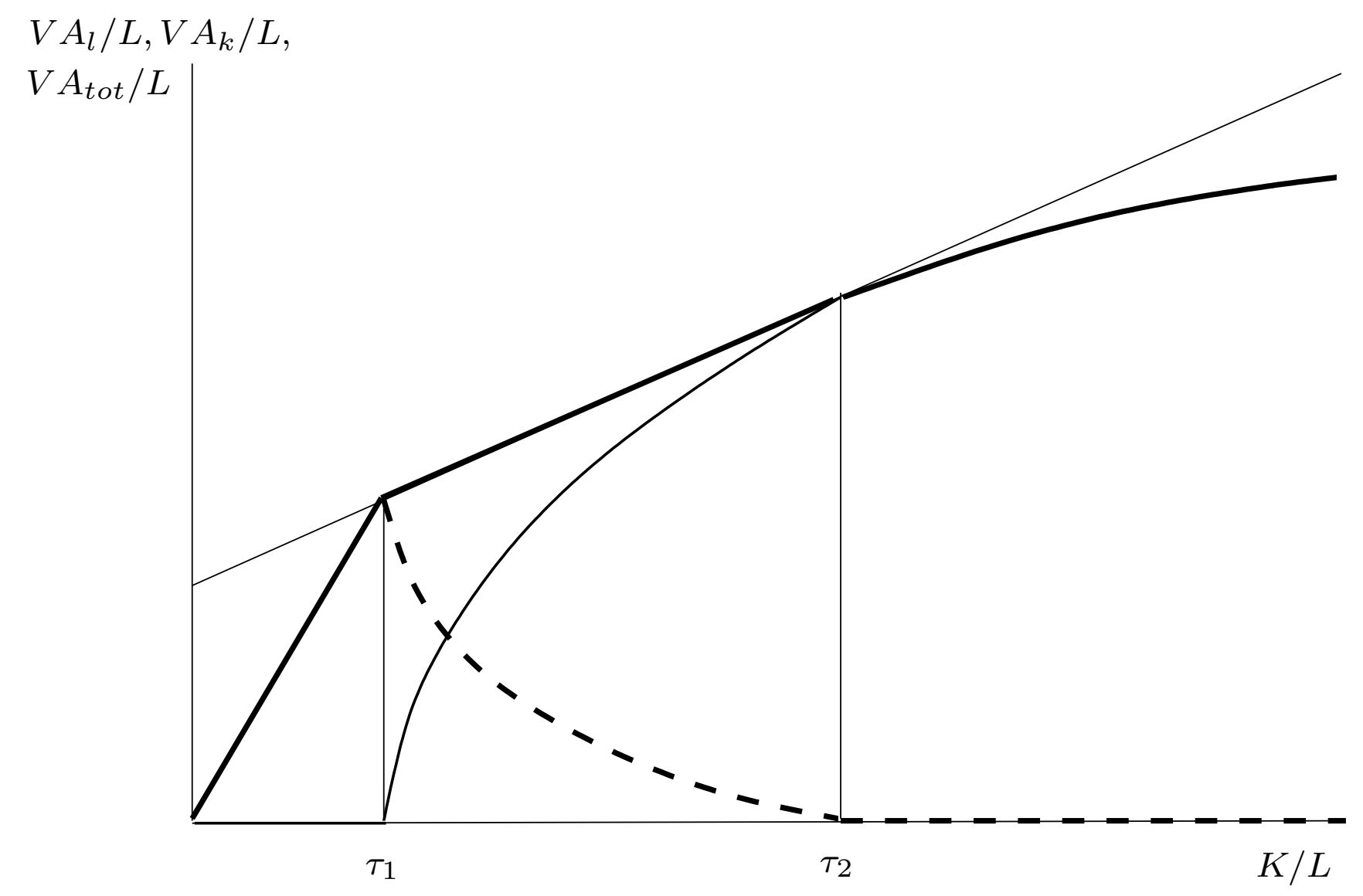

Figure 5: Production patterns and value-added per worker with our simplifying assumptions. 


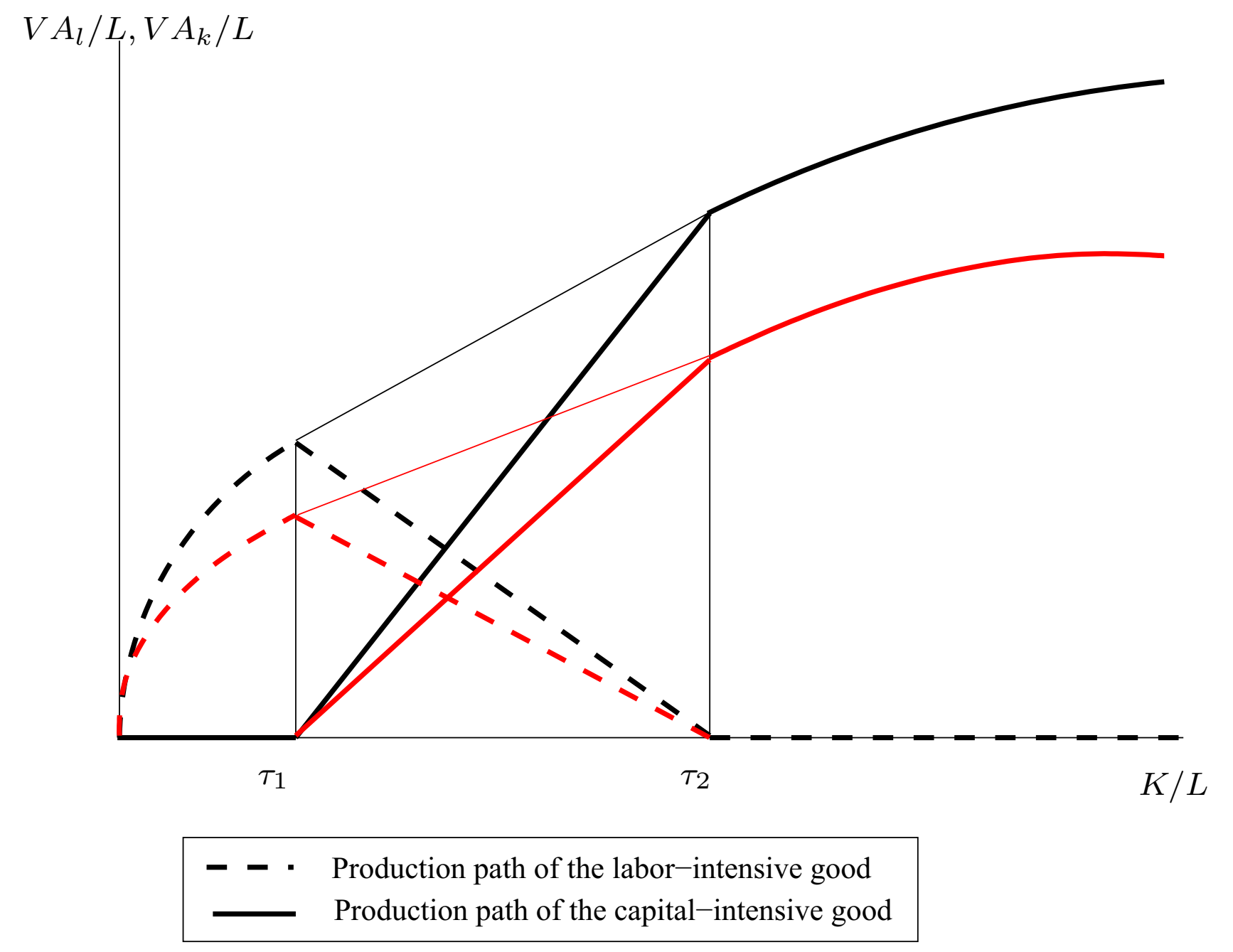

Figure 6: Production patterns in the $2 \times 2 \mathrm{HO}$ model and the scale effect. 


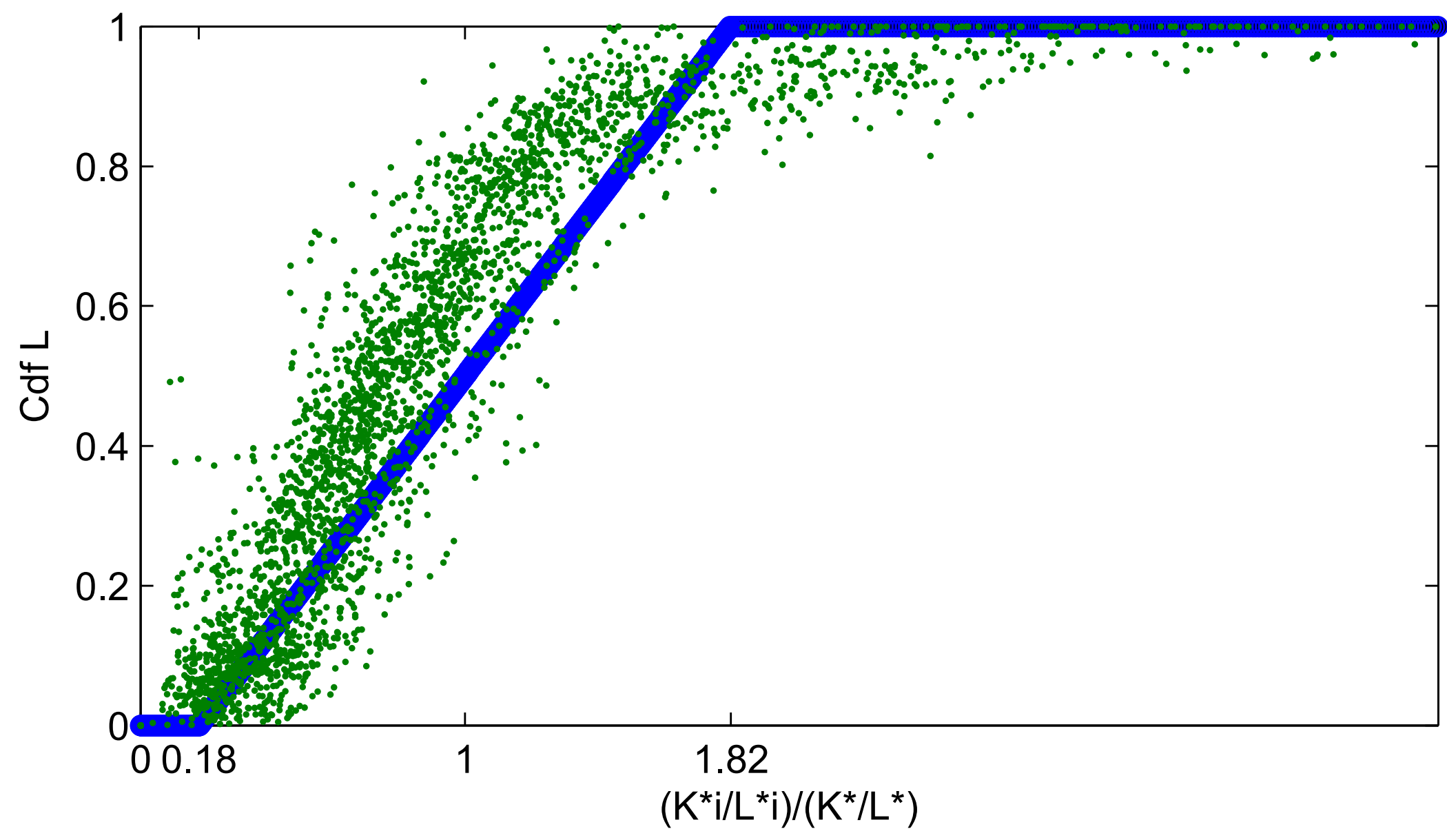

Figure 7: Distribution of labor across industries. 

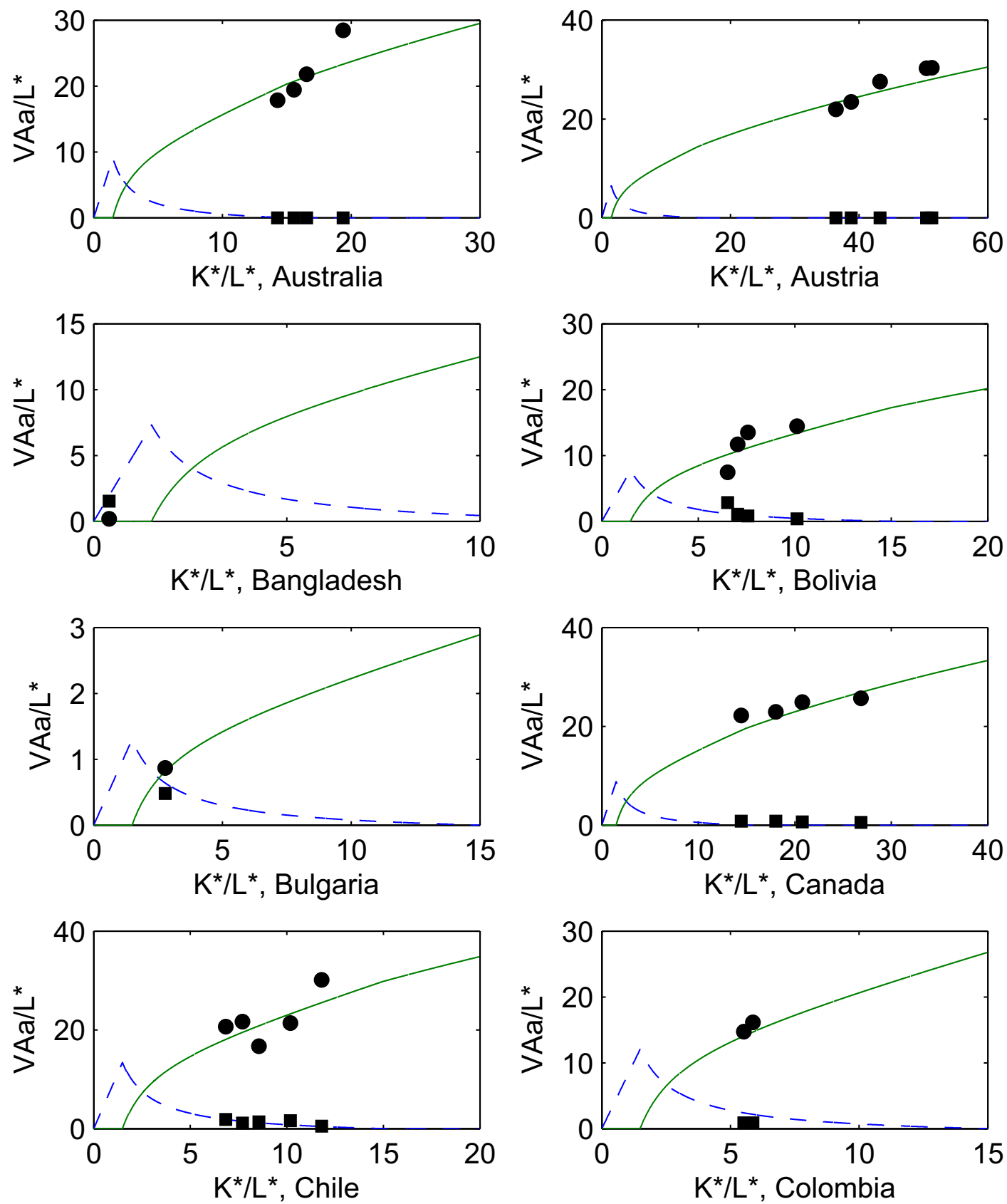

Figure 8: Development paths for the two HO aggregates, actual and estimated (aggregate-time dummies omitted).

Notes: Squares indicate actual $V A_{l n}^{t} / L_{n}^{t *}$ against $K_{n}^{* t} / L_{n}^{* t}$ for the different dates. Filled circles indicate actual $V A_{k n}^{t} / L_{n}^{* t}$ against $K_{n}^{* t} / L_{n}^{* t}$ for the different dates. Curves show the estimated development paths for the aggregates using Table 4 and Equations 12-13. All numbers in thousands of 1996 U.S. dollars. 

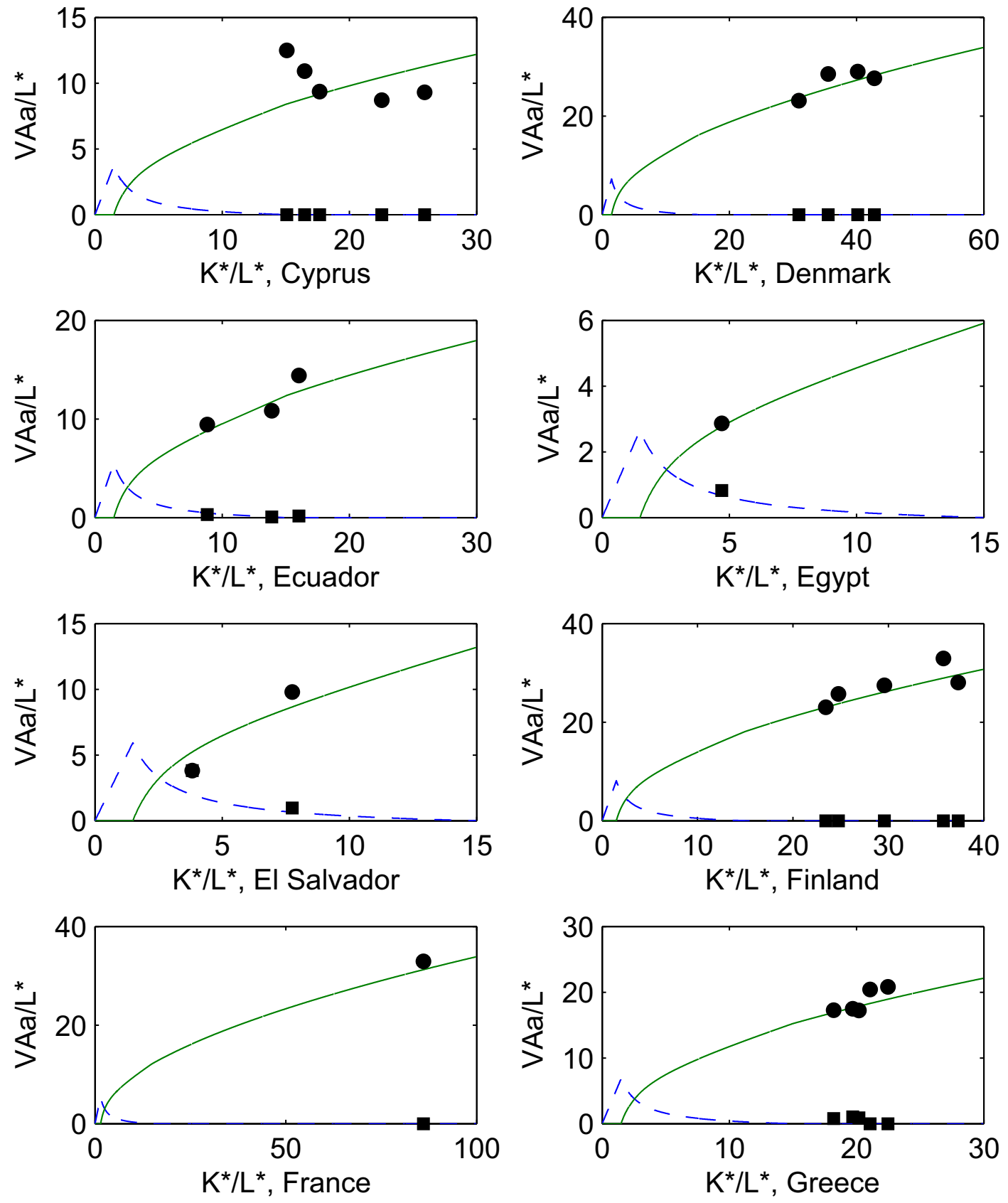

Figure 9: Development paths for the two HO aggregates, actual and estimated (aggregate-time dummies omitted), continued.

Notes: Squares indicate actual $V A_{l n}^{t} / L_{n}^{* t}$ against $K_{n}^{* t} / L_{n}^{* t}$ for the different dates. Filled circles indicate actual $V A_{k n}^{t} / L_{n}^{* t}$ against $K_{n}^{* t} / L_{n}^{* t}$ for the different dates. Curves show the estimated development paths for the aggregates using Table 4 and Equations 12-13. All numbers in thousands of 1996 U.S. dollars. 

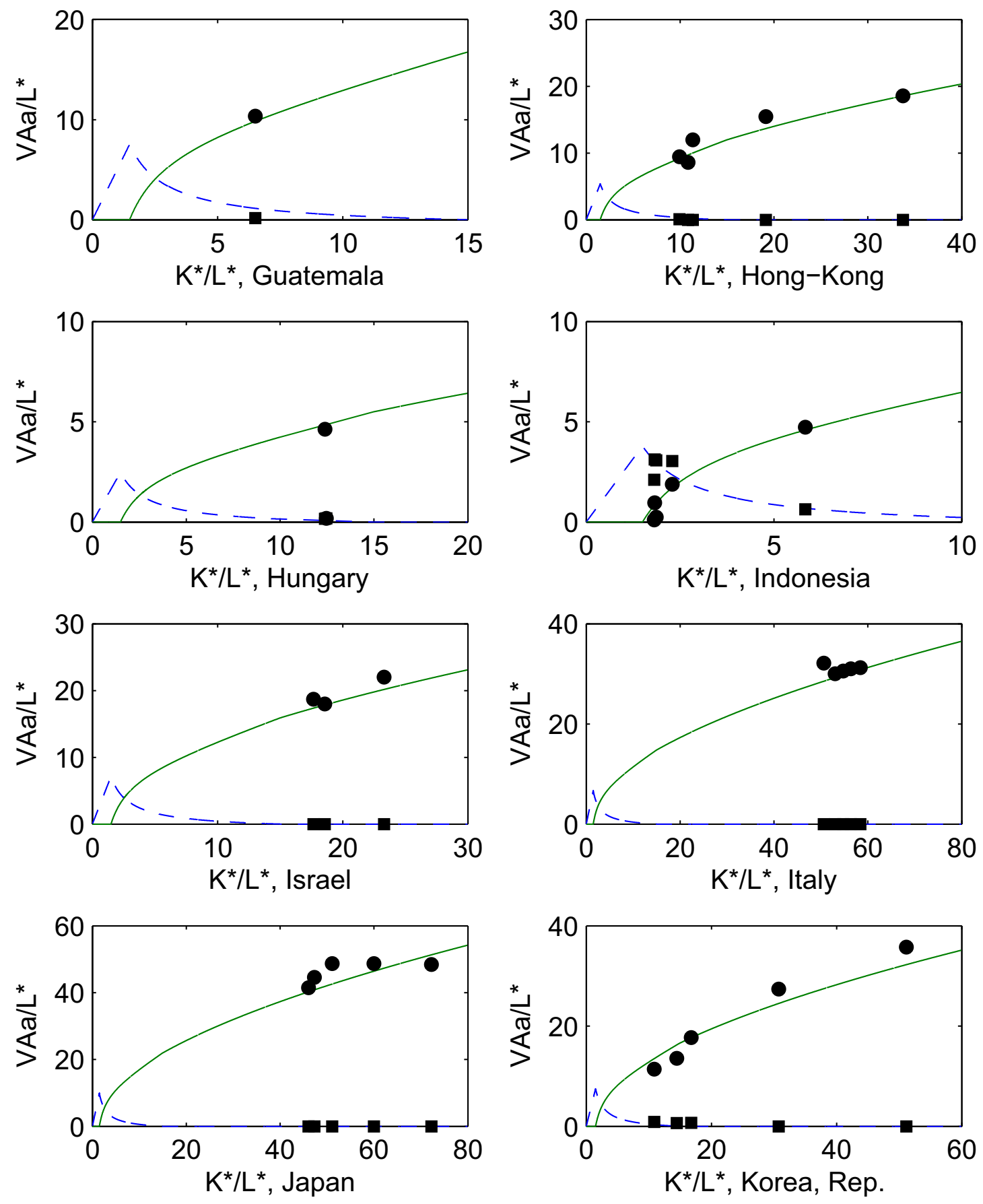

Figure 10: Development paths for the two HO aggregates, actual and estimated (aggregate-time dummies omitted), continued.

Notes: Squares indicate actual $V A_{l n}^{t} / L_{n}^{* t}$ against $K_{n}^{* t} / L_{n}^{* t}$ for the different dates. Filled circles indicate actual $V A_{k n}^{t} / L_{n}^{* t}$ against $K_{n}^{* t} / L_{n}^{* t}$ for the different dates. Curves show the estimated development paths for the aggregates using Table 4 and Equations 12-13. All numbers in thousands of 1996 U.S. dollars. 

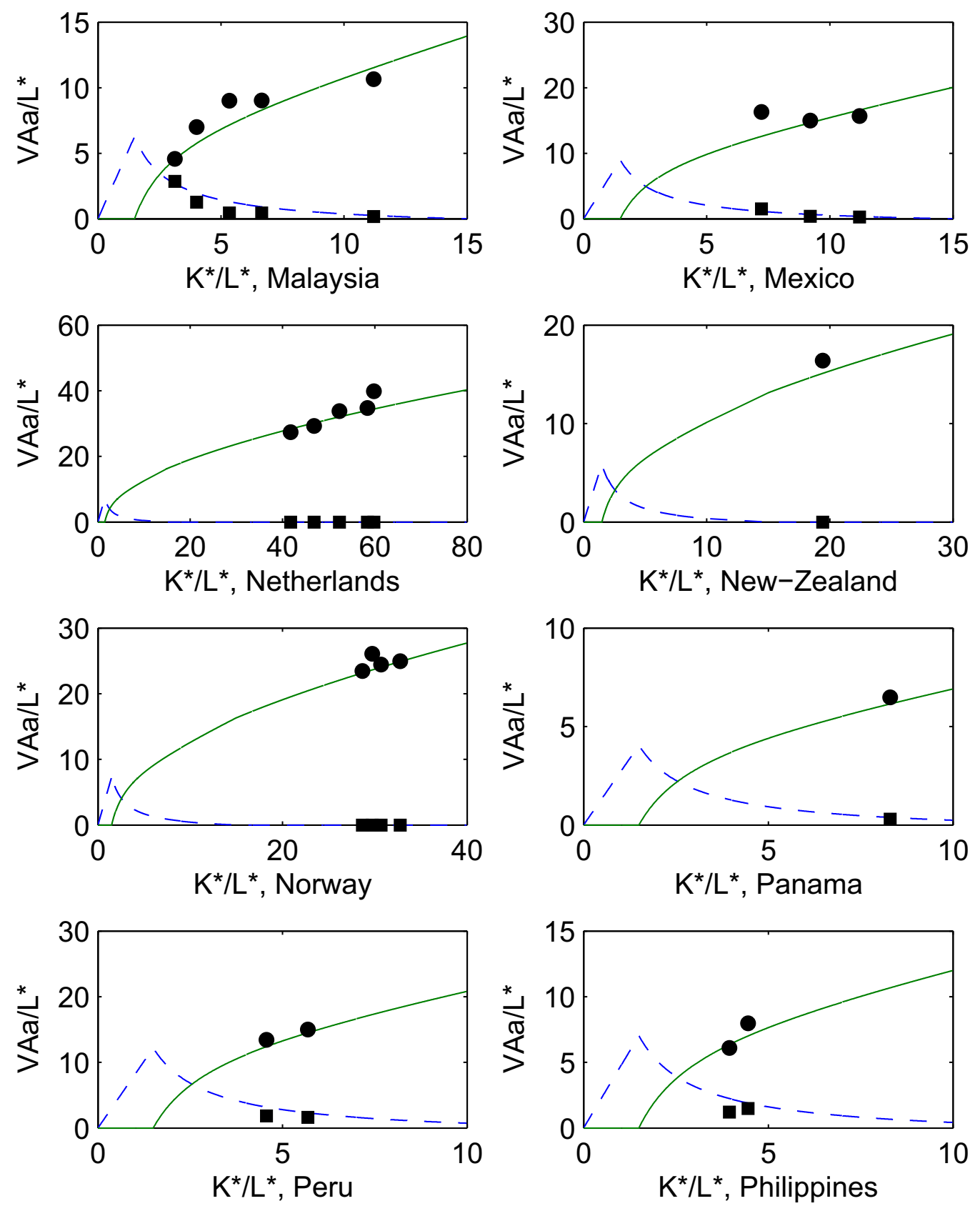

Figure 11: Development paths for the two HO aggregates, actual and estimated (aggregate-time dummies omitted), continued.

Notes: Squares indicate actual $V A_{l n}^{t} / L_{n}^{* t}$ against $K_{n}^{* t} / L_{n}^{* t}$ for the different dates. Filled circles indicate actual $V A_{k n}^{t} / L_{n}^{* t}$ against $K_{n}^{* t} / L_{n}^{* t}$ for the different dates. Curves show the estimated development paths for the aggregates using Table 4 and Equations 12-13. All numbers in thousands of 1996 U.S. dollars. 

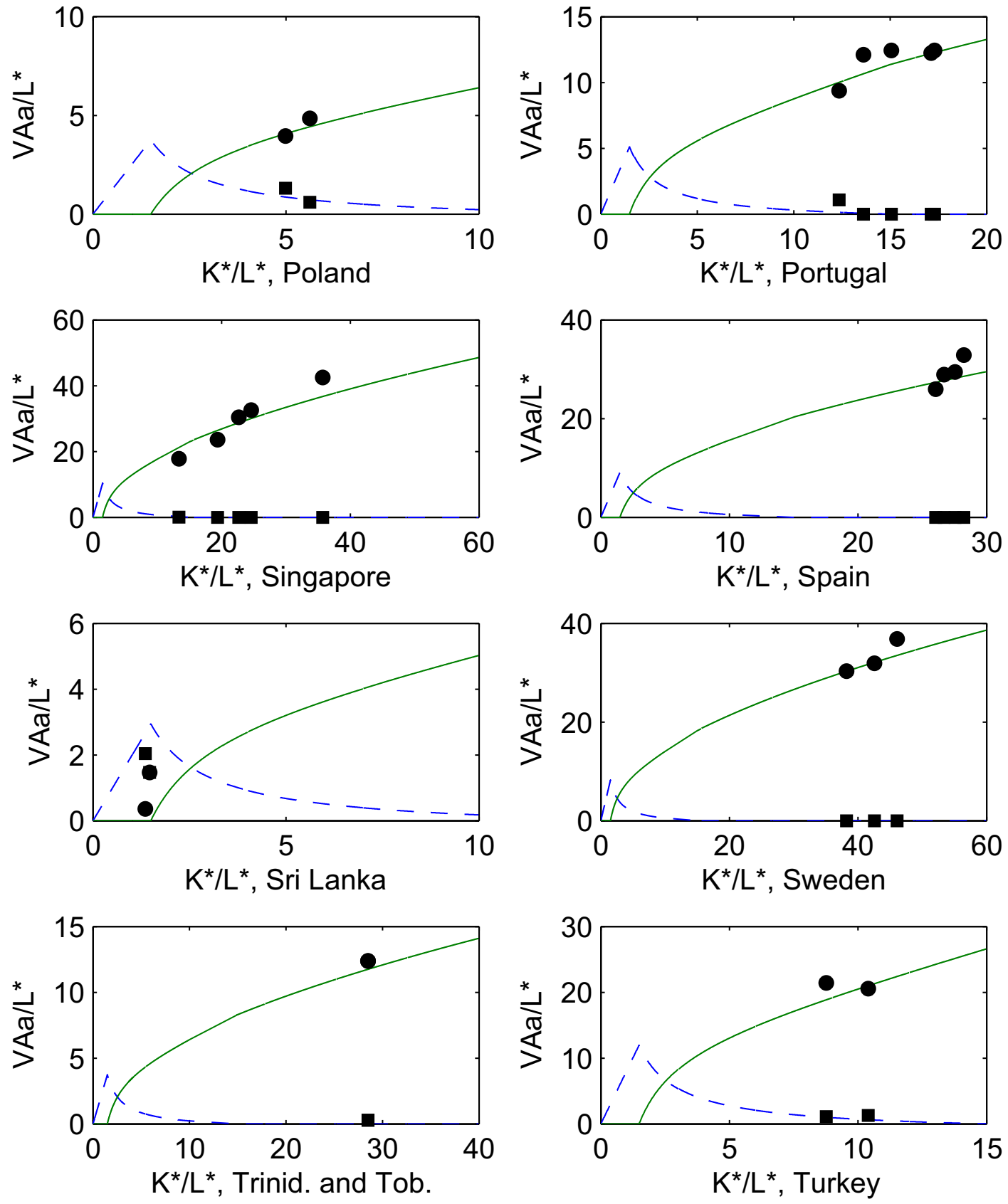

Figure 12: Development paths for the two HO aggregates, actual and estimated (aggregate-time dummies omitted), continued.

Notes: Squares indicate actual $V A_{l n}^{t} / L_{n}^{* t}$ against $K_{n}^{* t} / L_{n}^{* t}$ for the different dates. Filled circles indicate actual $V A_{k n}^{t} / L_{n}^{* t}$ against $K_{n}^{* t} / L_{n}^{* t}$ for the different dates. Curves show the estimated development paths for the aggregates using Table 4 and Equations 12-13. All numbers in thousands of 1996 U.S. dollars. 

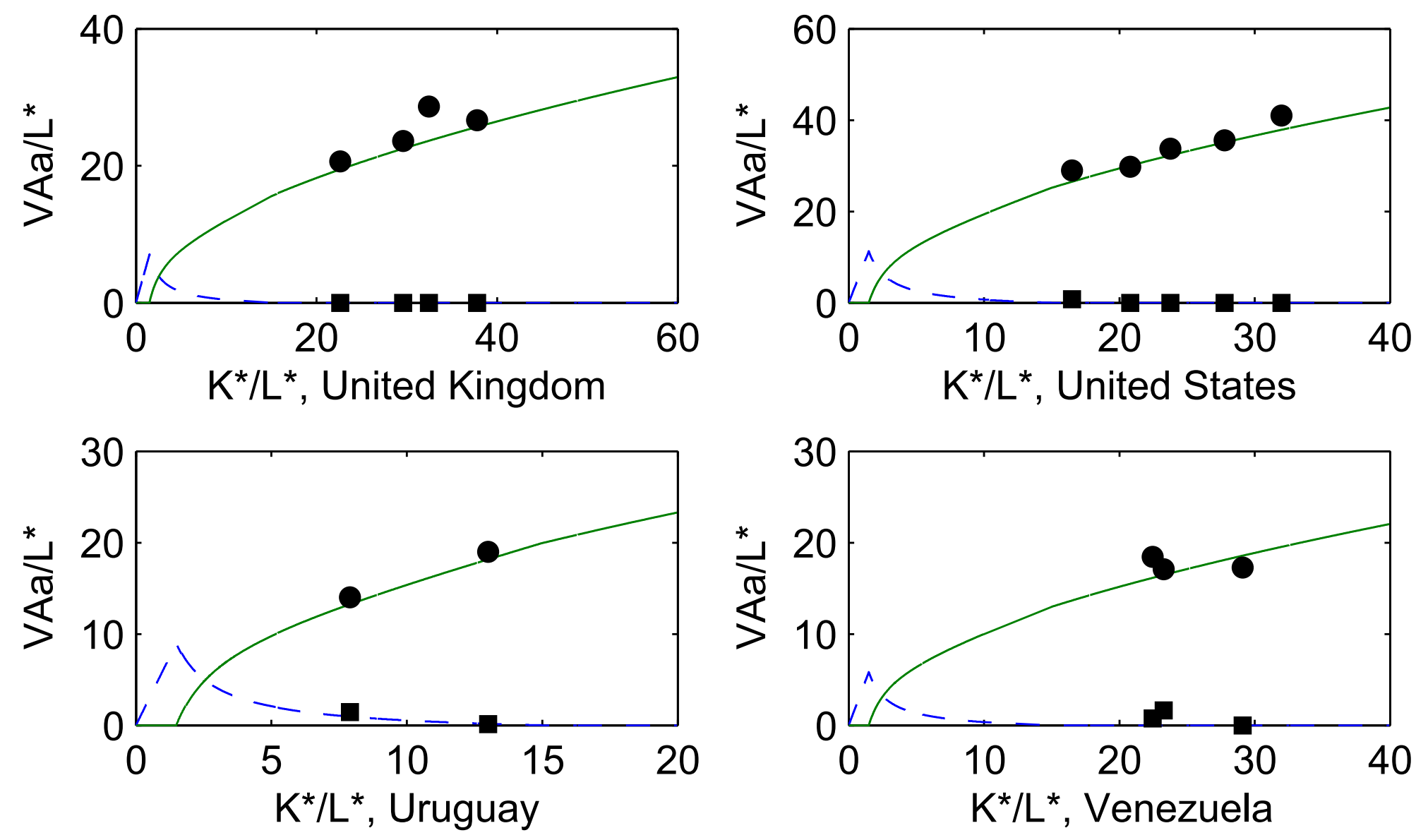

Figure 13: Development paths for the two HO aggregates, actual and estimated (aggregate-time dummies omitted), continued.

Notes: Squares indicate actual $V A_{l n}^{t} / L_{n}^{* t}$ against $K_{n}^{* t} / L_{n}^{* t}$ for the different dates. Filled circles indicate actual $V A_{k n}^{t} / L_{n}^{* t}$ against $K_{n}^{* t} / L_{n}^{* t}$ for the different dates. Curves show the estimated development paths for the aggregates using Table 4 and Equations 12-13. All numbers in thousands of 1996 U.S. dollars. 


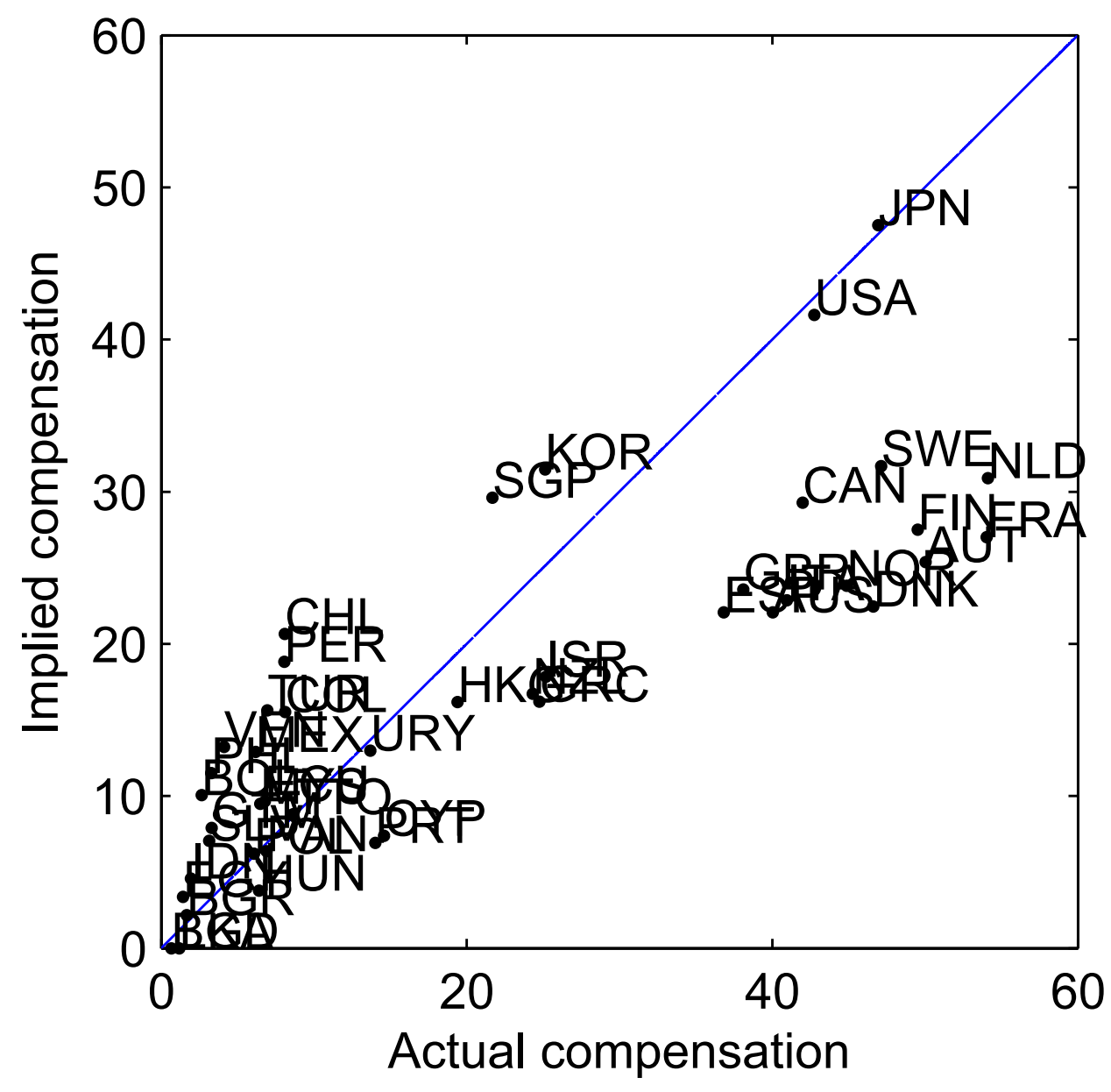

Figure 14: Annual compensation per employee in 1996, actual and implied by the model (in thousands of 1996 U.S. dollars). 


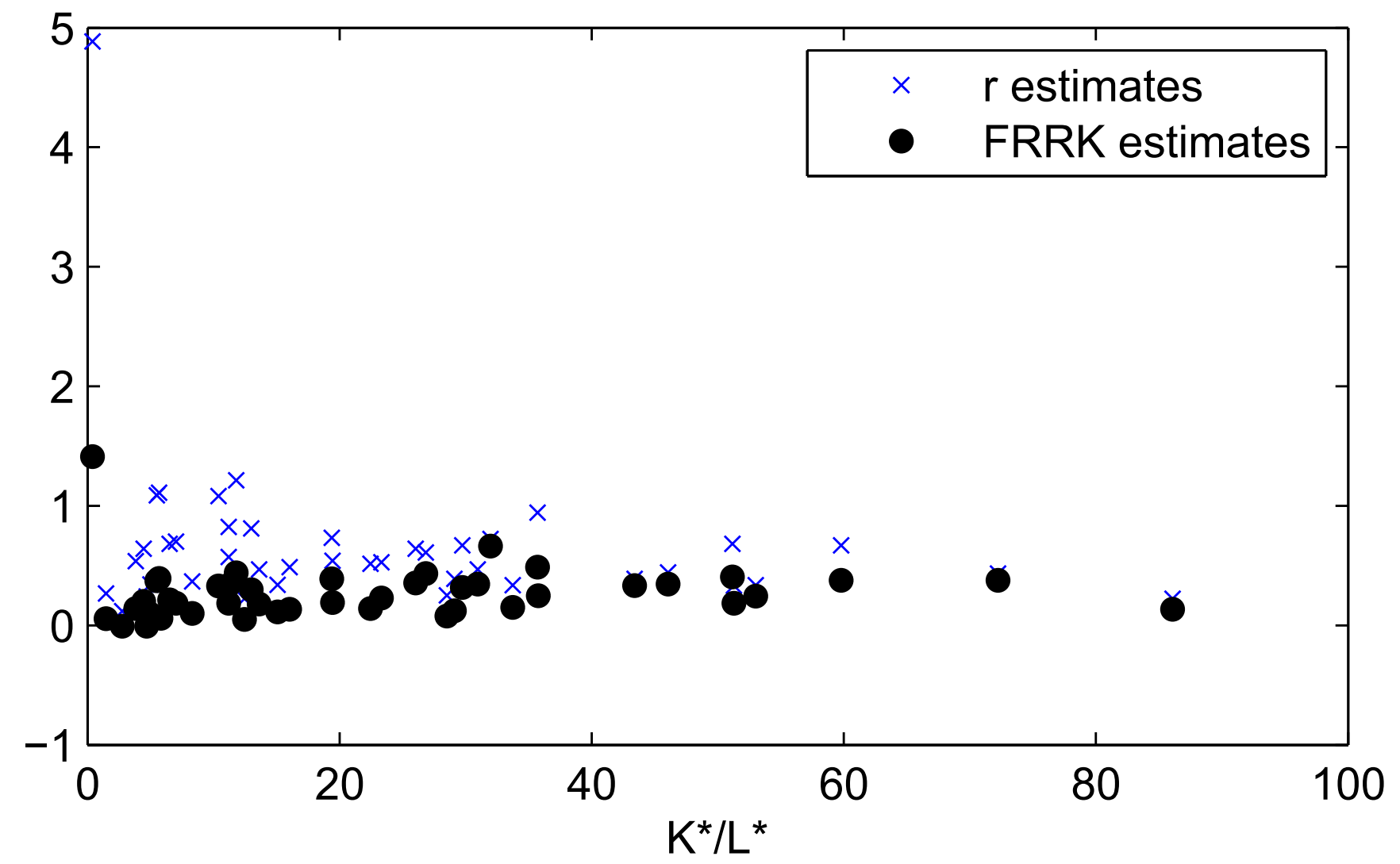

Figure 15: Estimated returns to capital $\left(\hat{r}_{n}\right)$ and financial rates of return to capital $\left(\widehat{F R R K}{ }_{n}\right)$. Notes: The computations are explained in the text. The capital-labor ratios are in thousands of 1996 U.S. dollars of capital per quality-equivalent worker. 


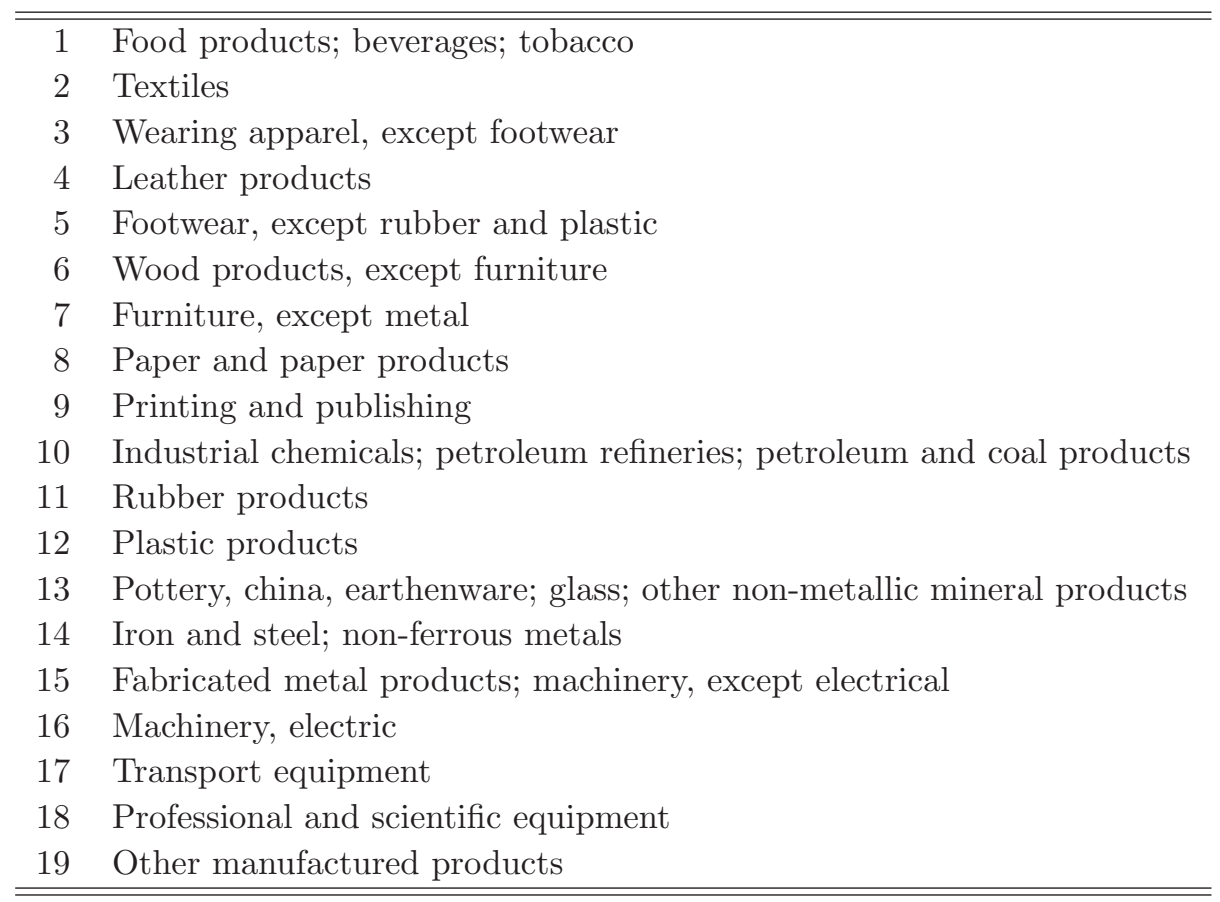

Table 1: List of sectors. 


\begin{tabular}{|c|c|c|c|c|c|c|c|c|c|c|c|c|}
\hline Country & Abbr. & $\frac{z_{K, U S A}}{z_{K n}}$ & $\begin{array}{c}1976- \\
\widehat{z}_{L n} \\
\end{array}$ & $\begin{array}{r}1980 \\
K_{n}^{*} / L_{n}^{*}\end{array}$ & $\begin{array}{c}1981- \\
\widehat{z}_{L n} \\
\end{array}$ & $\begin{array}{r}1985 \\
K_{n}^{*} / L_{n}^{*}\end{array}$ & $\begin{array}{c}1986- \\
\widehat{z}_{L n} \\
\end{array}$ & $\begin{array}{r}1990 \\
K_{n}^{*} / L_{n}^{*}\end{array}$ & $\begin{array}{c}1991- \\
\widehat{z}_{L n} \\
\end{array}$ & $\begin{array}{r}1995 \\
K_{n}^{*} / L_{n}^{*}\end{array}$ & $\begin{array}{c}1996- \\
\widehat{z}_{L n} \\
\end{array}$ & $\begin{array}{r}2000 \\
K_{n}^{*} / L_{n}^{*}\end{array}$ \\
\hline Australia & AUS & 1.63 & 2.23 & 14,273 & 2.24 & 15,553 & 2.25 & 16,543 & 2.28 & 19,369 & na & na \\
\hline Austria & AUT & 1.36 & 2.08 & 36,396 & 2.15 & 38,781 & 2.14 & 43,242 & 2.16 & 50,471 & 2.20 & 51,296 \\
\hline Bangladesh & BGD & 3.32 & na & na & na & na & na & na & na & na & 1.35 & 398 \\
\hline Bolivia & BOL & 2.88 & 1.48 & 6,522 & na & na & 1.56 & 10,111 & 1.62 & 7,577 & 1.66 & 7,041 \\
\hline Bulgaria & BGR & 2.18 & na & na & na & na & na & na & na & na & 2.14 & 2,771 \\
\hline Canada & $\mathrm{CAN}$ & 1.24 & 2.31 & 14,443 & 2.35 & 18,029 & 2.34 & 20,779 & 2.44 & 26,851 & na & na \\
\hline Chile & $\mathrm{CHL}$ & 2.42 & 1.71 & 8,555 & 1.75 & 10,188 & 1.84 & 6,834 & 1.93 & 7,705 & 1.97 & 11,799 \\
\hline Colombia & $\mathrm{COL}$ & 2.51 & na & na & na & na & 1.58 & 5,870 & 1.62 & 5,517 & na & na \\
\hline Cyprus & CYP & 1.96 & 1.81 & 25,902 & 1.94 & 22,545 & 2.06 & 17,648 & 2.10 & 16,471 & 2.13 & 15,083 \\
\hline Denmark & DNK & 1.15 & 2.17 & 42,815 & 2.21 & 40,197 & 2.29 & 35,523 & 2.30 & 30,953 & na & na \\
\hline Ecuador & $\overline{\mathrm{ECU}}$ & 2.52 & 1.60 & 8,831 & na & na & na & na & 1.79 & 13,905 & 1.83 & 16,030 \\
\hline Egypt & EGY & 4.46 & na & na & na & na & na & na & na & na & 1.62 & 4,698 \\
\hline El Salvador & SLV & 2.68 & na & na & na & na & na & na & 1.47 & 7,752 & 1.52 & 3,821 \\
\hline Finland & FIN & 1.61 & 2.00 & 23,442 & 2.03 & 24,760 & 2.14 & 29,572 & 2.26 & 37,314 & 2.31 & 35,758 \\
\hline France & FRA & 1.13 & na & na & na & na & na & na & na & na & 2.10 & 86,083 \\
\hline Greece & GRC & 2.55 & 1.77 & 18,206 & 1.86 & 20,182 & 1.94 & 19,703 & 2.01 & 21,059 & 2.08 & 22,460 \\
\hline Guatemala & GTM & 2.65 & na & na & na & na & na & na & 1.34 & 6,511 & na & na \\
\hline Hong-Kong & $\mathrm{HKG}$ & 1.60 & 1.73 & 10,837 & 1.83 & 9,939 & 1.93 & 11,362 & 2.05 & 19,140 & 2.12 & 33,734 \\
\hline Hungary & HUN & 2.03 & na & na & na & na & na & na & 1.93 & 12,391 & 1.95 & 12,467 \\
\hline Indonesia & IDN & 2.91 & 1.33 & 1,811 & 1.4 & 1,865 & 1.41 & 1,822 & 1.46 & 2,290 & 1.55 & 5,834 \\
\hline Ireland & IRL & 1.84 & 1.90 & 13,856 & 1.97 & 17,971 & 2.04 & 20,757 & 2.11 & 22,265 & 2.15 & 23,878 \\
\hline Israel & ISR & 1.82 & na & na & na & na & 2.11 & 17,674 & 2.12 & 18,575 & 2.15 & 23,311 \\
\hline Italy & ITA & 1.11 & 1.70 & 50,636 & 1.73 & 54,745 & 1.79 & 58,393 & 1.85 & 56,404 & 1.90 & 53,015 \\
\hline Japan & JPN & 0.99 & 1.99 & 46,072 & 2.07 & 47,305 & 2.15 & 51,086 & 2.22 & 59,982 & 2.25 & 72,247 \\
\hline Korea, Rep & $\mathrm{KOR}$ & 1.47 & 1.81 & 10,860 & 1.97 & 14,486 & 2.14 & 16,789 & 2.28 & 30,764 & 2.37 & 51,167 \\
\hline Malaysia & MYS & 2.33 & 1.49 & 3,126 & 1.55 & 4,006 & 1.62 & 5,341 & 1.81 & 6,657 & 1.94 & 11,205 \\
\hline Mexico & MEX & 2.08 & na & na & na & na & 1.66 & 7,225 & 1.77 & 9,206 & 1.83 & 11,203 \\
\hline Netherlands & NLD & 1.54 & 1.99 & 41,752 & 2.04 & 46,835 & 2.08 & 52,319 & 2.13 & 58,426 & 2.18 & 59,792 \\
\hline New Zealand & NZL & 2.14 & na & na & na & na & 2.32 & 19,428 & na & na & na & na \\
\hline Norway & NOR & 1.78 & 2.02 & 24,651 & 2.07 & 28,669 & 2.28 & 30,692 & 2.43 & 32,757 & 2.45 & 29,726 \\
\hline Panama & PAN & 2.33 & na & na & na & na & na & na & na & na & 2.02 & 8,297 \\
\hline Peru & PER & 2.46 & na & na & na & na & na & na & 1.88 & 4,566 & 1.98 & 5,686 \\
\hline Philippines & PHL & 2.45 & na & na & na & na & na & na & 2.05 & 3,947 & 2.1 & 4,451 \\
\hline Poland & POL & 2.22 & na & na & na & na & na & na & 2.09 & 5,620 & 2.12 & 4,986 \\
\hline Portugal & PRT & 1.95 & 1.48 & 17,132 & 1.53 & 17,302 & 1.61 & 15,059 & 1.68 & 12,355 & 1.73 & 13,610 \\
\hline Singapore & SGP & 1.73 & 1.46 & 13,372 & 1.49 & 19,381 & 1.61 & 22,670 & 1.82 & 24,583 & 1.96 & 35,708 \\
\hline Spain & ESP & 1.55 & na & na & 1.72 & 27,543 & 1.80 & 28,232 & 1.88 & 26,695 & 1.96 & 26,036 \\
\hline Sri Lanka & LKA & 2.29 & na & na & na & na & na & na & 1.71 & 1,357 & 1.75 & 1,466 \\
\hline Sweden & SWE & 1.09 & 2.10 & 38,229 & 2.15 & 42,543 & 2.16 & 46,070 & na & na & na & na \\
\hline Trinidad and Tobaggo & TTO & 1.83 & na & na & na & na & na & na & na & na & 1.82 & 28,500 \\
\hline Turkey & TUR & 2.78 & na & na & na & na & na & na & 1.62 & 8,764 & 1.67 & 10,394 \\
\hline United Kingdom & GBR & 0.99 & 1.91 & 22,629 & 1.94 & 29,579 & 1.98 & 32,458 & 2.03 & 37,764 & 2.07 & 43,391 \\
\hline USA & USA & 1.00 & 2.48 & 16,509 & 2.58 & 20,809 & 2.61 & 23,782 & 2.65 & 27,769 & 2.67 & 31,986 \\
\hline Uruguay & URY & 2.26 & na & na & na & na & na & na & 1.81 & 7,894 & 1.85 & 13,004 \\
\hline Venezuela & VEN & 2.15 & 1.55 & 23,269 & 1.67 & 22,461 & na & na & na & na & 1.73 & 29,121 \\
\hline
\end{tabular}

Notes: Capital and labor are measured in quality-equivalent units. Capital is in 1996 U.S. dollars. na = not available.

Table 2: Geographic coverage and some key variables. 


\begin{tabular}{|c|c|c|c|c|c|}
\hline Sector & $1976-1980$ & 1981-1985 & 1986-1990 & 1991-1995 & $1996-2000$ \\
\hline \multicolumn{6}{|l|}{ USA } \\
\hline Wearing apparel & 2,486 & 3,074 & 3,732 & 4,212 & 6,077 \\
\hline Furniture & 5,556 & 6,610 & 7,142 & 7,968 & 7,859 \\
\hline Footwear & 3,387 & 4,501 & 6,569 & 8,184 & 10,198 \\
\hline Leather products & 4,505 & 6,663 & 8,762 & 10,319 & 11,384 \\
\hline Other manufactured products & 7,739 & 10,172 & 10,685 & 11,527 & 13,356 \\
\hline Metal products & 9,064 & 10,820 & 12,318 & 13,374 & 15,772 \\
\hline Printing and publishing & 10,131 & 11,715 & 13,617 & 16,033 & 17,283 \\
\hline Wood products & 15,083 & 18,901 & 17,273 & 17,569 & 20,188 \\
\hline Textiles & 11,677 & 14,140 & 15,936 & 17,755 & 23,125 \\
\hline Professional and scientific equipment & 10,816 & 14,111 & 14,008 & 19,684 & 23,935 \\
\hline Plastic products & 13,699 & 16,252 & 17,021 & 19,768 & 23,348 \\
\hline Rubber products & 20,177 & 24,953 & 25,778 & 26,889 & 29,581 \\
\hline Machinery & 11,438 & 15,367 & 23,715 & 29,989 & 40,030 \\
\hline Food products & 19,536 & 24,444 & 28,095 & 30,694 & 33,888 \\
\hline Transport equipment & 14,864 & 22,078 & 25,464 & 32,455 & 38,785 \\
\hline Pottery and glass & 24,084 & 30,521 & 30,931 & 32,878 & 35,971 \\
\hline Iron and steel & 34,727 & 48,129 & 54,576 & 57,392 & 59,187 \\
\hline Paper products & 33,066 & 42,994 & 53,878 & 64,536 & 72,448 \\
\hline Chemicals and petroleum & 58,629 & 71,918 & 80,348 & 94,804 & 108,280 \\
\hline \multicolumn{6}{|l|}{ Malaysia } \\
\hline Wearing apparel & 825 & 750 & 882 & 1,145 & 2,042 \\
\hline Footwear & 2,925 & 3,653 & 2,918 & 1,558 & 3,404 \\
\hline Leather products & 4,282 & 2,687 & 1,746 & 2,005 & 4,228 \\
\hline Other manufactured products & 1,032 & 1,113 & 1,533 & 2,046 & 3,762 \\
\hline Furniture & 1,347 & 1,551 & 2,772 & 2,109 & 2,901 \\
\hline Machinery & 2,628 & 2,805 & 3,264 & 4,008 & 6,885 \\
\hline Rubber products & 3,103 & 3,180 & 3,459 & 4,405 & 6,979 \\
\hline Professional and scientific equipment & 2,570 & 3,790 & 4,285 & 4,919 & 7,416 \\
\hline Plastic products & 2,637 & 2,656 & 3,853 & 5,265 & 9,102 \\
\hline Wood products & 3,290 & 3,666 & 5,184 & 5,359 & 7,489 \\
\hline Printing and publishing & 10,754 & 6,126 & 5,369 & 5,454 & 6,544 \\
\hline Transport equipment & 2,056 & 3,243 & 4,683 & 5,916 & 10,716 \\
\hline Food products & 3,997 & 5,422 & 6,687 & 7,055 & 9,726 \\
\hline Metal products & 3,072 & 3,300 & 5,116 & 7,482 & 12,714 \\
\hline Textiles & 3,013 & 3,470 & 4,166 & 7,847 & 15,825 \\
\hline Pottery and glass & 4,613 & 5,629 & 8,757 & 10,709 & 19,515 \\
\hline Iron and steel & 3,192 & 5,518 & 17,446 & 13,340 & 16,603 \\
\hline Paper products & 3,992 & 7,857 & 11,792 & 21,449 & 27,455 \\
\hline Chemicals and petroleum & 7,046 & 12,384 & 19,507 & 34,281 & 55,319 \\
\hline
\end{tabular}

Notes: Capital and labor are measured in effective units. Capital is in 1996 U.S. dollars. Sectors in increasing order of capital-intensity for the period 1991-1995.

Table 3: Industry capital-labor ratios in the United States and Malaysia. 


\begin{tabular}{|c|c|c|c|c|c|}
\hline Variable & Estimate & s.e. & Variable & Estimate & s.e. \\
\hline$\delta_{k}^{1976-1980}$ & 0 & - & $\delta_{l}^{1976-1980}$ & -0.01 & $(0.33)$ \\
\hline$\delta_{k}^{1981-1985}$ & 0.01 & $(0.02)$ & $\delta_{l}^{1981-1985}$ & -0.04 & $(0.40)$ \\
\hline$\delta_{k}^{1986-1990}$ & 0.09 & $(0.02)$ & $\delta_{l}^{1986-1990}$ & -0.16 & $(0.31)$ \\
\hline$\delta_{k}^{1991-1995}$ & 0.05 & $(0.02)$ & $\delta_{l}^{1991-1995}$ & -0.28 & $(0.23)$ \\
\hline$\delta_{k}^{1996-2000}$ & 0.05 & $(0.02)$ & $\delta_{l}^{1996-2000}$ & -0.21 & $(0.31)$ \\
\hline$\alpha$ & 0.14 & $(0.04)$ & & & \\
\hline$\beta$ & 0.46 & $(0.04)$ & & & \\
\hline \multicolumn{6}{|l|}{$r_{1 n}$} \\
\hline Country & Estimate & s.e. & Country & Estimate & s.e. \\
\hline Australia & 6.11 & $(1.06)$ & Japan & 6.61 & $(1.17)$ \\
\hline Austria & 4.35 & $(0.77)$ & Korea, Rep. & 5.01 & $(0.86)$ \\
\hline Bangladesh & 4.89 & $(4.66)$ & Malaysia & 4.19 & $(0.57)$ \\
\hline Bolivia & 5.19 & $(0.70)$ & Mexico & 6.03 & $(0.86)$ \\
\hline Bulgaria & 0.87 & $(1.17)$ & Netherlands & 4.91 & $(0.87)$ \\
\hline Canada & 5.91 & $(1.03)$ & New Zealand & 3.95 & $(0.75)$ \\
\hline Chile & 8.98 & $(1.22)$ & Norway & 4.92 & $(0.86)$ \\
\hline Colombia & 8.06 & $(0.93)$ & Panama & 2.70 & $(0.65)$ \\
\hline Cyprus & 2.52 & $(0.46)$ & Peru & 8.14 & $(0.92)$ \\
\hline Denmark & 4.83 & $(0.85)$ & Philippines & 4.69 & $(0.72)$ \\
\hline Ecuador & 3.72 & $(0.65)$ & Poland & 2.50 & $(0.57)$ \\
\hline Egypt & 1.78 & $(0.81)$ & Portugal & 3.42 & $(0.60)$ \\
\hline El Salvador & 3.97 & $(0.65)$ & Singapore & 6.92 & $(1.19)$ \\
\hline Finland & 5.45 & $(0.95)$ & Spain & 6.11 & $(1.06)$ \\
\hline France & 3.66 & $(0.67)$ & Sri Lanka & 1.97 & $(1.04)$ \\
\hline Greece & 4.58 & $(0.80)$ & Sweden & 5.50 & $(0.98)$ \\
\hline Guatemala & 5.05 & $(0.85)$ & Trinid. and Tob. & 2.50 & $(0.50)$ \\
\hline Hong-Kong & 3.61 & $(0.61)$ & Turkey & 8.01 & $(1.15)$ \\
\hline Hungary & 1.66 & $(0.40)$ & United Kingdom & 4.69 & $(0.82)$ \\
\hline Indonesia & 2.53 & $(0.57)$ & United States & 7.58 & $(1.31)$ \\
\hline Israel & 4.79 & $(0.84)$ & Uruguay & 6.01 & $(0.94)$ \\
\hline Italy & 4.45 & $(0.79)$ & Venezuela & 3.91 & $(0.69)$ \\
\hline \multicolumn{6}{|l|}{ Root MSE } \\
\hline Capital-intensive aggr. & 402 & & Labor-intensive aggr. & 1,648 & \\
\hline
\end{tabular}

Notes: The Table reports the estimates of System 10-11 with Non Linear Least Squares. These estimates take the HO aggregate cutoff $q=3,000$ to define the two HO aggregates, and the cone cutoffs $\tau_{1}=1,500$ and $\tau_{2}=15,000$ to define the cones. The estimation is run with Ireland excluded.

Table 4: Coefficient estimates for the $2 \times 2$ model. 


\begin{tabular}{|c|c|c|}
\hline Country & $\widehat{r}_{n}$ & $\widehat{F R R K}_{n}$ \\
\hline Australia & 0.73 & 0.39 \\
\hline Austria & 0.33 & 0.18 \\
\hline Bangladesh & 4.89 & 1.41 \\
\hline Bolivia & 0.70 & 0.18 \\
\hline Bulgaria & 0.12 & -0.01 \\
\hline Canada & 0.61 & 0.43 \\
\hline Chile & 1.21 & 0.44 \\
\hline Colombia & 1.09 & 0.37 \\
\hline Cyprus & 0.34 & 0.11 \\
\hline Denmark & 0.47 & 0.35 \\
\hline Ecuador & 0.49 & 0.13 \\
\hline Egypt & 0.24 & -0.01 \\
\hline El Salvador & 0.54 & 0.14 \\
\hline Finland & 0.49 & 0.25 \\
\hline France & 0.22 & 0.14 \\
\hline Greece & 0.51 & 0.14 \\
\hline Guatemala & 0.68 & 0.21 \\
\hline Hong-Kong & 0.34 & 0.15 \\
\hline Hungary & 0.22 & 0.05 \\
\hline Indonesia & 0.34 & 0.06 \\
\hline Israel & 0.53 & 0.23 \\
\hline Italy & 0.34 & 0.24 \\
\hline Japan & 0.43 & 0.38 \\
\hline Korea, Rep. & 0.68 & 0.40 \\
\hline Malaysia & 0.57 & 0.19 \\
\hline Mexico & 0.82 & 0.34 \\
\hline Netherlands & 0.67 & 0.38 \\
\hline New Zealand & 0.54 & 0.19 \\
\hline Norway & 0.67 & 0.32 \\
\hline Panama & 0.37 & 0.10 \\
\hline Peru & 1.11 & 0.39 \\
\hline Philippines & 0.64 & 0.20 \\
\hline Poland & 0.34 & 0.09 \\
\hline Portugal & 0.47 & 0.18 \\
\hline Singapore & 0.94 & 0.49 \\
\hline Spain & 0.64 & 0.35 \\
\hline Sri Lanka & 0.27 & 0.06 \\
\hline Sweden & 0.44 & 0.35 \\
\hline Trinidad Tobago & 0.25 & 0.08 \\
\hline Turkey & 1.08 & 0.33 \\
\hline United Kingdom & 0.39 & 0.33 \\
\hline United States & 0.72 & 0.66 \\
\hline Uruguay & 0.81 & 0.30 \\
\hline Venezuela & 0.39 & 0.12 \\
\hline Average & 0.65 & 0.27 \\
\hline Std. Dev. & 0.70 & 0.23 \\
\hline
\end{tabular}

Table 5: Estimated returns to capital $\left(\hat{r}_{n}\right)$ and financial rates of return to capital $\left(\widehat{F R R K}_{n}\right)$ for the period 1996-2000. 


\begin{tabular}{|c|c|c|c|c|c|c|}
\hline Country & $\begin{array}{c}\Delta K_{n}^{*} / L_{n}^{*} \\
(1976-1980)-(1986-1990)\end{array}$ & Between & Within & $\begin{array}{c}\Delta K_{n}^{*} / L_{n}^{*} \\
(1986-1990)-(1996-2000)\end{array}$ & Between & Within \\
\hline Australia & 2,270 & $-27 \%$ & $127 \%$ & na & na & na \\
\hline Austria & 6,846 & $-1 \%$ & $101 \%$ & 8,054 & $-48 \%$ & $148 \%$ \\
\hline Bolivia & 3,589 & $-26 \%$ & $126 \%$ & $-3,070$ & $-18 \%$ & $118 \%$ \\
\hline Canada & 6,336 & $-12 \%$ & $112 \%$ & na & na & na \\
\hline Chile & $-1,712$ & $37 \%$ & $63 \%$ & 4,965 & $1 \%$ & $99 \%$ \\
\hline Cyprus & $-8,254$ & $7 \%$ & $93 \%$ & $-2,565$ & $-93 \%$ & $193 \%$ \\
\hline Denmark & $-7,292$ & $29 \%$ & $71 \%$ & na & na & na \\
\hline Finland & 6,130 & $3 \%$ & $97 \%$ & 6,186 & $-27 \%$ & $127 \%$ \\
\hline Greece & 1,497 & $-10 \%$ & $110 \%$ & 2,757 & $43 \%$ & $57 \%$ \\
\hline Hong-Kong & 525 & $25 \%$ & $75 \%$ & 22,372 & $-9 \%$ & $109 \%$ \\
\hline Indonesia & 11 & $-560 \%$ & $660 \%$ & 4,012 & $-9 \%$ & $109 \%$ \\
\hline Israel & na & na & na & 5,637 & $-4 \%$ & $104 \%$ \\
\hline Italy & 7,757 & $-56 \%$ & $156 \%$ & $-5,378$ & $141 \%$ & $-41 \%$ \\
\hline Japan & 5,014 & $-68 \%$ & $168 \%$ & 21,161 & $-3 \%$ & $103 \%$ \\
\hline Korea & 5,929 & $-8 \%$ & $108 \%$ & 34,378 & $5 \%$ & $95 \%$ \\
\hline Malaysia & 2,215 & $-5 \%$ & $105 \%$ & 5,864 & $0 \%$ & $100 \%$ \\
\hline Mexico & na & na & na & 3,978 & $-27 \%$ & $127 \%$ \\
\hline Netherlands & 10,567 & $25 \%$ & $75 \%$ & 7,473 & $-13 \%$ & $113 \%$ \\
\hline Norway & 6,041 & $-6 \%$ & $106 \%$ & -966 & $231 \%$ & $-131 \%$ \\
\hline Portugal & $-2,073$ & $56 \%$ & $44 \%$ & $-1,449$ & $196 \%$ & $-96 \%$ \\
\hline Singapore & 9,298 & $-9 \%$ & $109 \%$ & 13,038 & $-4 \%$ & $104 \%$ \\
\hline Spain & na & na & na & $-2,196$ & $98 \%$ & $2 \%$ \\
\hline Sweden & 7,841 & $-6 \%$ & $106 \%$ & na & na & na \\
\hline United Kingdom & 9,829 & $-6 \%$ & $106 \%$ & 10,933 & $-14 \%$ & $114 \%$ \\
\hline USA & 7,273 & $-7 \%$ & $107 \%$ & 8,204 & $-1 \%$ & $101 \%$ \\
\hline
\end{tabular}

Note: Capital and labor are measured in quality-equivalent units. Capital is in 1996 U.S. dollars. The decomposition is described in Equation 17 and explained in the text. na = not available.

Table 6: A decomposition of the changes in the capital-labor ratios. 